NBER WORKING PAPER SERIES

INTERPRETING TESTS OF FORWARD

DISCOUNT BIAS USING SURVEY DATA

ON EXCHANGE RATE EXPECTATIONS

Jeffrey A. Frankel

Kenneth A. Froot

Working Paper No. 1963

NATIONAL BUREAU OF ECONOMIC RESEARCH 1050 Massachusetts Avenue

Cambridge, MA 02138

June 1986

The research reported here is part of the NBER's research program in International studies. Any opinions expressed are those of the authors and not those of the National Bureau of Economic Research. 
Working Paper \#1963

June 1986

\author{
Interpreting Tests of Forward Discount Bias Using \\ Survey Data on Exchange Rate Expectations
}

\begin{abstract}
Survey data on exchange rate expectations are used to divide the forward discount into expected depreciation and a risk premium. Our starting point is the common test of whether the forward discount is an unbiased predictor of future changes in the spot rate. We use the surveys to decompose the bias into a portion attributable to the risk premium and a portion attributable to systematic prediction errors. The survey data suggest that our findings of both unconditional and conditional bias are overwhelmingly due to systematic expectational errors. Regressions of future changes in the spot rate against the forward discount do not yield insights into the sign, size or variability of the risk premium as is usually thought. We test directly the hypothesis of perfect substitutability, and find support for it in that changes in the forward discount reflect, one for one, changes in expected depreciation. The "random-walk" view that expected depreciation is zero is thus rejected; expected depreciation is even significantly more variable than the risk premium. In fact. investors would do better if they always reduced fractionally the magnitude of expected depreciation. This is the same result that Bilson and many others have found with forward market data, but now it cannot be attributed to a risk premium.
\end{abstract}

Jeffrey A. Franke]

Department of Economics

University of California

Berkeley, CA 94720
Kenneth A. Froot

Sloan School of Management MIT

Cambridge, MA 02139 


\title{
Interpreting Tests of Forward Discount Bias Using Survey Data on Exchange Rate Expectations
}

\author{
Kenneth A. Froot \\ Sloan School of Management \\ Massachusetts Institute of Technology \\ Cambridge, Massachusetts 02139 \\ Jeffrey A. Frankel \\ Department of Economics \\ University of California, Berkeley \\ Berkeley, California 94720
}

\section{INTRODUCTION}

The forward exchange rate is surely the jack-of-all-trades of international financial economics. Whenever researchers need a variable representing investor expectations of future spot rates, the forward rate is the first to come to mind. On the other hand, the forward rate is frequently used to measure the empirically elusive foreign exchange risk premium.

These two conflicting roles are most evident in the large literature testing whether the forward discount is an unbiased predictor of the future change in the spot exchange rate. ${ }^{1}$ Most of the studies that test the unbiasedness

We would like to thank Greg Connor and Joe Mattey for helpful comments, Barbara Bruer John Calverley, Louise Cordova, Kathryn Dominguez, Laura Knoy, Stephen Marris, and Phil Young for help in obtaining data, the National Science Foundation (under grant no. SES8218300), the Lnstitute for Business and Economic Research at U. C. Berkeley, and the Alfred P. Sloan Foundation's doctoral dissertation program for research support.

1 References include Tryon (1979), Levich (1979), Bilson (1981a), Longworth (1981).

Hsieh (1982), Fama (1984), Huang (1984), Park (1984) and Hodrick and Srivastava (1986). For a recent survey of the literature and additional citations see Boothe and Longworth
(1886). 
hypothesis reject it, and they generally agree on the direction of bias. They tend to disagree, however, about whether the bias is evidence of a risk premium or of a violation of rational expectations. For example, studies by Longworth (1981) and Bilson (1981a) assume that investors are risk neutral, so that the systematic component of exchange rate changes in excess of the forward discount is interpreted as evidence of a failure of rational expectations. On the other hand, Hsieh (1984) and most others attribute the same systematic component to a time-varying risk premium that separates the forward discount from expected depreciation.

Investigations by Fama (1984) and Hodrick and Srivastava (1986) have recently gone a step further, interpreting the bias not only as evidence of a risk premium, but also as evidence that the variance of the risk premium is greater than the variance of expected depreciation. Bilson (1985) terms this view a new "empirical paradigm" because it incorporates an essentially static model of exchange rate expectations; changes in the forward discount predominantly reflect changes in the risk premium rather than changes in expected depreciation. Often cited in support of this view is the work of Meese and Rogoff (1983), who find that a random walk model consistently forecasts future spot rates better than alternative models, including the forward rate.

But one cannot address without additional information the basic issues of whether systematic expectational errors or the risk premium are alone responsible for the repeatedly biased forecasts of the forward discount for whether it is some combination of the two), let alone whether the risk premium is more variable than expected depreciation. In this paper we use survey data on exchange rate expectations in an attempt to help resolve these issues. The surveys allow us to divide the forward discount into its two components - expected depreciation and the risk premium -- and to inspect separately the properties 
of each.

Though surveys of agents' expectations may in general be less desirable than data on agents' actual market behavior, in this case the merit of a new data source lies in what could not have been learned without it. One particular advantage of the surveys is that our estimates of the risk premium do not depend on the validity of any specific model or assumptions. As a consequence we can test directly whether investors regard assets denominated in different currencies as perfect substitutes. A second advantage is that, with the issue of the risk premium's existence tentatively resolved, we can then test the hypothesis of forward rate unbiasedness and come away with a clear idea of how much bias is due to the risk premium and how much is due to systematic expectational errors. A third advantage of the surveys (which cover a variety of sample periods and forecast horizons) is that they can help us gain a sense for the accuracy of earlier interpretations given to the large number of rejections of the forward rate unbiasedness hypothesis.

The paper is organized as follows. Section 2 presents some simple descriptive statistics from the survey data. Here the focus is primarily on the unconditional prediction errors of the forward discount. In section 3, we perform the standard (conditional) test of forward discount unbiasedness, and use the surveys to decompose the bias into a component attributable to systematic expectational errors and a component attributable to the risk premium. In section 4. we test formally whether the risk premium component is significantly different from zero, that is, we test whether investors regard positions in different currencies as perfect substitutes. In section 5, we test formally whether the expectational errors component is significantly different from zero, that is, we ask if the survey expectations are rational in the sense that they are formed in a manner consistent with the true spot process. Finally, section 6 offers our 
conclusions.

\section{DESCRIPTIVE STATISTICS}

Our exchange rate expectations data come from three independent surveys. The first survey source is Money Market Services (MMS), Inc. Every two weeks from January 1983 to October 1984, MMS spoke by phone with an average of 30 currency traders or currency-room economists at major international banks. Respondents were asked for their expectations of the value of the pound, mark, Swiss franc and yen against the dollar in two weeks and three months time. From October 1984 to February 1986, MMS conducted its survey every week, asking for expectations one week and one month into the future. The Economist Financial Report has conducted telephone interviews with currency traders at 14 leading international banks one day each six weeks beginning in June, 1981. On each occasion, respondents reported their expectations of the value of the pound, French franc, mark, Swiss franc and yen at three-, six- and twelve-month horizons. Finally, the Amex Bank Review (Amex) surveys 250-300 central and private bankers, corporate treasurers and finance directors, and economists, and records their expectations of the value of the pound, French franc, mark, Swiss franc and yen against the dollar at six-month and twrelve-month horizons. Most of these data sets are discussed and analyzed in Frankel and Froot (1986).2

Naturally, the benefits that survey data provide do not come without possible costs. The presence of heterogeneous beliefs, the use of the median response, the lack of perfect synchronization, and the sheer volatility of the spot rate all make some measurement error in the survey data likely. We present results in section 4 which suggest that the surveys are surprisingly

\footnotetext{
2 Another paper that uses the MMS data is Dominguez (1986).
} 
"clean". Nevertheless, we try to use only tests that are robust to the presence of random measurement error in the data. ${ }^{3}$ In order to take advantage of the complete sample of data available (the three sources contain over 1,450 data points), we used every available opportunity to raise our sample sizes. The data are frequently pooled across currencies. We also employ a method-of-moments estimation procedure which allows us to pool the data across different forecast horizons.

\subsection{Decomposition of Forward Rate Prediction Frrors}

The simplest test for whether the forward discount is an unbiased predictor of the future spot rate is a test for unconditional bias in the forward rate prediction errors. These errors are defined as:

$$
f d_{t}^{k}-\Delta s_{t+k}=\left(f d_{t}^{k}-\Delta s_{t+k}^{*}\right)+\left(\Delta s_{t+k}^{*}-\Delta s_{t+k}\right) \equiv r p_{t}^{k}+\eta_{t+k}^{k}
$$

where $f d_{t}^{k}$ is the forward discount (the log of the current forward rate minus the $\log$ of the current spot rate, $f_{t}^{k}-s_{t}$ ) expressed in terms of domestic currency, and $\Delta s_{t+k}$ and $\Delta s_{t+k}^{e}$ are the log of the actual spot rate and expected spot rate $k$ periods into the future, respectively, minus the log of the current spot rate. Equation (1) thus defines the risk premium, $r p_{t}^{k}$, as the expected excess return required by investors in order to hold an open position in domestic currency at time $t$ and $\eta_{t+k}^{k}$ as the expectational prediction error, realized at time $t+k$. If exchange rate risk is completely diversifiable and expectations are rational, then the forward rate prediction errors should be purely random. 4

\footnotetext{
s Also, we experimented with different approximations to the precise survey and forecast dates of the Amex survey, which was conducted by mail over a period of up to a month. We used the average of the 30 days during the survey and also the mid-point of the survey period to construct reference sets. Both gave very similar results, so that only results from the former sample were reported.

4 Under perfect substitutability, expected real, and not nominal, profits should be zero; the two differ because of Jensen's inequality (see Engel, 1084). We do not incorporate the effects of purchasing power uncertainty in this paper, however. One might expect the effects are small: the standard deviation of unexpected changes in the inflation rate are about 1/30 the size of the standard deviation in exchange rate changes (Litterman, 1980. and the results in Tables 1, 2 and 3 of this paper).
} 
Table 1 reports the time series means of the forward discount, ex post change in the spot rate and the forward rate prediction error in equation (1). sampled on the days when surveys were conducted. ${ }^{5}$ In several cases (particularly the MMS three-month data and the Economist and Amex twelve-month data), we can reject the hypothesis that the forward rate is on average an unbiased predictor of the future spot rate. ${ }^{6}$ The signs of the errors are clearly sensitive to the sample period; they are negative in the later MMS sample (October 1984 to February 1986) and in the Amex data from the late 1970s, but positive in between. Columns (1) and (2) of Table 1 show that such variation is due to substantial swings in average ex post exchange rate changes from sample period to sample period and not due to swing $s$ in the forward discount.

Without any additional information on investors' expected future spot rate, $s_{t+k}$. one would have to assume that the risk premium is zero in order to interpret equation (1) as a test of market efficiency. Alternatively, if one wishes to interpret equation (1) as a test for the existence of a risk premium, the assumption of rational expectations is required (i.e., $\eta_{t+k}^{k}$ is serially uncorrelated and $\left.E\left(\eta_{t+k}^{k} \mid r p_{t}^{k}\right)=0\right)$. Thus the results in Table 1 could be interpreted as evidence that investors made repeated for ecasting mistakes during some the survey periods, or that investors distinguished between assets denominated in different currencies on the basis of risk (or else some combination of these polar points of view)?

5 DRI provided us with daily forward and spot exchange rates, computed as the average of the noon-time bid and ask rates.

- The Economist surveys, MMS one-month and three-month surveys, and the Amex twelve-month survey were conducted at intervals shorter than their respective forecast horizons. This implies that the prediction errars of the forward discount and of the survey expectations, in Tables 1 and 2 respectively, are not all independent, even under the hypothesis of rational expectations. For the Economist and MMS data, the standard deviation of the means were estimated by a method of moments procedure discussed in the following section. For the Amex data, confidence intervals were constructed assuming that the number of degrees of freedom is equal to the number of nonoverlapping observations. This latter procedure implies that t-tests reported for the Amex data are lower bounds.

7 Other potential candidates to explain the non-zero forward rate prediction errors are the so-called "peso problem" (but see Frankel, 1985) and the convexity term due to Jensen's inequality (see McCulloch, 1975). 
Table 1

SPOT AND FORNARD MARKET SUMMARY STAIISTICS

12 percent per annua!

\begin{tabular}{|c|c|c|c|c|c|c|c|}
\hline & & & & $\begin{array}{c}\text { (2) } \\
\text { FORNARD } \\
\text { DISCOUNT } \\
f(t)-5(t)\end{array}$ & $\begin{array}{c}\text { (1) } \\
\text { ACTUAL } \\
\text { CHANGE } \\
5(t+1)-5(t)\end{array}$ & $\begin{array}{r}\text { FORNA } \\
\text { PREDI } \\
\text { flt }\end{array}$ & $\begin{array}{l}-(2) \\
\text { DISCOUNT } \\
\text { IION ERROR } \\
-5(t+1)\end{array}$ \\
\hline $\begin{array}{l}\text { FORECAST } \\
\text { HORIZON }\end{array}$ & $\begin{array}{l}\text { SURVEY } \\
\text { SOURCE }\end{array}$ & DATES & N & Mean & Hean & Mean & $t$ stat \\
\hline $\begin{array}{l}1 \text { HEEK } \\
\text { IOIAL } \\
\text { UK } \\
\text { WG } \\
\text { SH } \\
\text { JA }\end{array}$ & MMS & $10 / 84-2 / 86$ & $\begin{array}{r}247 \\
62 \\
62 \\
61 \\
62\end{array}$ & $N A$ & $\begin{array}{l}20.20 \\
14.96 \\
21.36 \\
20.10 \\
24.39\end{array}$ & & \\
\hline 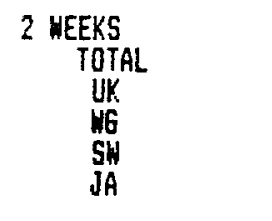 & Mas & $1 / 83-10 / 84$ & $\begin{array}{r}187 \\
47 \\
47 \\
46 \\
47\end{array}$ & NA & $\begin{array}{r}-12.35 \\
-16.15 \\
-15.19 \\
-13.86 \\
-4.23\end{array}$ & & \\
\hline $\begin{array}{c}\text { I MONIH } \\
\text { TOTAL } \\
\text { UK } \\
\text { WG } \\
\text { SH } \\
\text { JA }\end{array}$ & MHS & $10 / 84-2 / 86$ & $\begin{array}{r}176 \\
44 \\
44 \\
44 \\
44\end{array}$ & $\begin{array}{r}1.23 \\
-3.85 \\
3.23 \\
3.74 \\
1.68\end{array}$ & $\begin{array}{l}20.82 \\
10.13 \\
23.82 \\
21.76 \\
27.55\end{array}$ & $\begin{array}{l}-19.59 \\
-13.98 \\
-20.59 \\
-18.02 \\
-25.98\end{array}$ & $\begin{array}{l}-1.27 \\
-1.871 \\
-1.64 \\
-2.35 \text { It }\end{array}$ \\
\hline $\begin{array}{c}3 \text { MONTHS } \\
\text { TOIAL } \\
\text { UK } \\
\text { WG } \\
\text { SH } \\
\text { JA }\end{array}$ & MHS & $1 / 83-10 / 84$ & $\begin{array}{r}187 \\
47 \\
47 \\
46 \\
47\end{array}$ & $\begin{array}{l}3.75 \\
0.37 \\
4.68 \\
6.13 \\
3.85\end{array}$ & $\begin{array}{r}-10.77 \\
-13.92 \\
-13.68 \\
-12.61 \\
-2.90\end{array}$ & $\begin{array}{r}14.51 \\
14.29 \\
18.36 \\
18.74 \\
6.75\end{array}$ & $\begin{array}{ll}6.30 & 111 \\
3.00 & 411 \\
3.85 & 111 \\
3.93 & 111 \\
1.42 & \end{array}$ \\
\hline $\begin{array}{l}\text { TOTAL } \\
\text { UK. } \\
F R \\
\text { UG } \\
\text { SH } \\
\text { JA }\end{array}$ & ECONOHIST & $6 / 81-12 / 85$ & $\begin{array}{r}190 \\
38 \\
38 \\
38 \\
38 \\
38\end{array}$ & $\begin{array}{r}2.20 \\
-0.06 \\
-3.94 \\
4.36 \\
5.99 \\
4.67\end{array}$ & $\begin{array}{r}-0.84 \\
-6.43 \\
-4.43 \\
0.81 \\
1.47 \\
4.37\end{array}$ & $\begin{array}{l}3.04 \\
6.37 \\
0.49 \\
3.55 \\
4.52 \\
0.30\end{array}$ & $\begin{array}{l}0.81 \\
1.14 \\
0.09 \\
0.63 \\
0.81 \\
0.05\end{array}$ \\
\hline 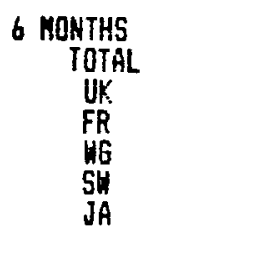 & ECONOHIST & $6 / 81-12 / 85$ & $\begin{array}{r}180 \\
36 \\
36 \\
36 \\
36 \\
36\end{array}$ & $\begin{array}{r}2.30 \\
0.31 \\
-4.14 \\
4.40 \\
6.01 \\
4.93\end{array}$ & $\begin{array}{l}-2.18 \\
-6.79 \\
-6.29 \\
-0.96 \\
-0.36 \\
3.52\end{array}$ & $\begin{array}{l}4.48 \\
7.10 \\
2.15 \\
5.36 \\
6.37 \\
1.41\end{array}$ & $\begin{array}{l}1.06 \\
1.12 \\
0.34 \\
0.85 \\
1.01 \\
0.22\end{array}$ \\
\hline $\begin{array}{l}\text { TOTaL } \\
\text { Early Period } \\
\text { Later Period }\end{array}$ & AMEX & $\begin{array}{l}1 / 76-8 / 85 \\
1 / 76-12 / 78 \\
6 / 81-8 / 95\end{array}$ & $\begin{array}{l}51 \\
26 \\
25\end{array}$ & $\begin{array}{l}2.07 \\
1.06 \\
3.12\end{array}$ & $\begin{array}{l}5.98 \\
8.98 \\
2.96\end{array}$ & $\begin{array}{r}-3.92 \\
-7.93 \\
0.26\end{array}$ & $\begin{array}{c}-1.50 \\
-2.83 \mathrm{IIt} \\
0.06\end{array}$ \\
\hline $\begin{array}{c}12 \text { MONTHS } \\
\text { TOTAL } \\
\text { UK } \\
\text { FR } \\
\text { HG } \\
\text { SH } \\
\text { JA }\end{array}$ & ECONOHIST & $6 / 81-12 / 85$ & $\begin{array}{r}195 \\
31 \\
31 \\
31 \\
3 ! \\
3 !\end{array}$ & $\begin{array}{r}2.58 \\
0.92 \\
-4.00 \\
4.42 \\
6.38 \\
5.17\end{array}$ & $\begin{array}{r}-6.42 \\
-9.47 \\
-11.20 \\
-5.60 \\
-5.75 \\
-0.08\end{array}$ & $\begin{array}{r}9.00 \\
10.39 \\
7.20 \\
10.02 \\
12.13 \\
5.25\end{array}$ & $\begin{array}{l}3.85141 \\
3.22 \text { 111 } \\
2.2314 \\
3.10114 \\
3.75144 \\
1.63\end{array}$ \\
\hline $\begin{array}{l}\text { TOTAL } \\
\text { Early Period } \\
\text { Later Period }\end{array}$ & A $A E Y$ & $\begin{array}{l}1 / 76-8 / 85 \\
1 / 76-12 / 79 \\
6 / 81-8 / 85\end{array}$ & $\begin{array}{l}46 \\
26 \\
20\end{array}$ & $\begin{array}{l}2.06 \\
0.93 \\
3.52\end{array}$ & $\begin{array}{r}2.02 \\
8.85 \\
-6.86\end{array}$ & $\begin{array}{r}0.04 \\
-7.92 \\
10.38\end{array}$ & $\begin{array}{l}0.02 \\
-2.36 \mathrm{tt} \\
9.42 \mathrm{t11}\end{array}$ \\
\hline
\end{tabular}

Notes: Standard Errors of means are conputed using method of uonents. Amex standard errors, however, are calculated using the nuber of nonover lapping observations and are thus upper bounds. Multi-country test

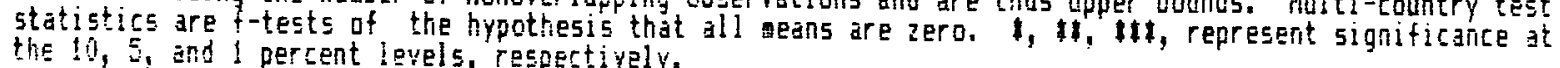


In Table 2 we use the survey data to separate the forward rate prediction errors into the two terms on the right-hand-side of equation (1): the risk premium and expectational errors. Here the conclusions concerning the nature of each are surprisingly very different from those one might draw from Table 1. Note first that the means of the risk premia measured in the survey data are large, averaging around an annualized 5 percent and reaching 9 percent in several cases. Second, and perhaps even more striking, is that nothing about the sign or magnitude of the risk premia as measured by the survey data can be inferred from the forward discount prediction errors. In fact, the premia in column (1) of Table 2 happen to be consistently opposite in sign from the forward rate errors. ${ }^{8}$ Third, the risk premia often appear negatively correlated with the forward rate errors, not just across data sets, but within each data set as well. The first column of Table 3 reports correlation coefficients for each currency and survey: 21 of the 33 estimates are less than zero. Charts 1 through 4 show the time series of the forward rate errors and the survey risk premia for each of the data sets. ${ }^{9}$ The graphs show how badly the forward prediction errors have measured the premia in the past.

Such a poor correspondence might suggest instead that the survey data are very imprecise measures of investors' true expectations. But, in the first place, it should be noted that findings of unconditional bias are unaffected by any measurement error in the survey data, provided the error is random. Positive and negative measurement errors should tend to cancel out, just as positive and negative prediction errors should tend to cancel out under the null hypothesis. In the second place, we offer an explicit estimate of the magnitude

$\theta$ This is the same as saying that the survey prediction errors are of the same sign as the forward rate errors, but have consistently larger absolute values.

- Graphs 1-3 use moving averages across all of the currencies included in the designated survey. The Amex data in Graph 4 were straightforward averages over the five currencies surveyed. 
Table?

SURUEY DATA SUMMERY STATISTICS

(t) percent per annua)

\begin{tabular}{|c|c|c|c|c|c|c|c|c|}
\hline \multirow[b]{2}{*}{$\begin{array}{l}\text { FORECAST } \\
\text { HORIZON }\end{array}$} & \multirow[b]{2}{*}{$\begin{array}{l}\text { SURVEY } \\
\text { SOURCE }\end{array}$} & \multirow[b]{2}{*}{ DATES } & \multirow[b]{2}{*}{ N } & \multicolumn{2}{|c|}{$\begin{array}{c}\text { (1) } \\
\text { RISt: } \\
\text { PREMIUM } \\
f(t)-E[s(t+1)]\end{array}$} & \multicolumn{2}{|c|}{ 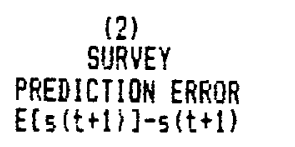 } & \multirow{2}{*}{$\begin{array}{l}(1)+(2) \\
\text { FORWARD DISCOUNT } \\
\text { PREOICTION ERROR } \\
f(t)-5(t+1)\end{array}$} \\
\hline & & & & Mean & $t$ stat & Mean & $t$ stat & \\
\hline 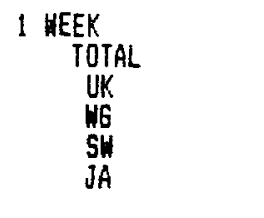 & Mhs & $10 / 84-2 / 86$ & $\begin{array}{r}247 \\
62 \\
62 \\
61 \\
62\end{array}$ & & NA & $\begin{array}{l}-19.17 \\
-27.79 \\
-18.52 \\
-11.27 \\
-18.99\end{array}$ & $\begin{array}{r}1.01 \\
-1.69 \\
-1.13 \\
-0.69 \\
-1.16\end{array}$ & NA \\
\hline 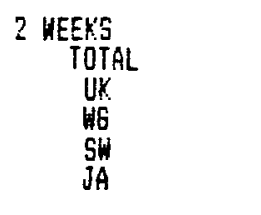 & MMS & $1 / 83-10 / 84$ & $\begin{array}{r}187 \\
47 \\
47 \\
46 \\
47\end{array}$ & & NA & $\begin{array}{l}16.57 \\
13.49 \\
20.28 \\
19.95 \\
12.63\end{array}$ & $\begin{array}{l}2.79 \mathrm{tt} \\
2.001 \\
3.00 \mathrm{111} \\
2.95 \mathrm{t11} \\
1.97\end{array}$ & NA \\
\hline $\begin{array}{c}\text { I MONTH } \\
\text { TOTAL } \\
\text { UK } \\
\text { WG } \\
\text { SH } \\
\text { JA }\end{array}$ & Mhs & $10 / 84-2 / 86$ & $\begin{array}{r}176 \\
44 \\
44 \\
44 \\
44\end{array}$ & $\begin{array}{r}3.86 \\
8.06 \\
5.49 \\
3.07 \\
-1.31\end{array}$ & $\begin{array}{l}3.05 \text { t1t } \\
2.59 \text { it1 } \\
2.25 \\
1.24 \\
-0.68\end{array}$ & $\begin{array}{l}-23.44 \\
-22.04 \\
-26.08 \\
-21.09 \\
-24.57\end{array}$ & $\begin{array}{l}1.47 \\
-1.94 \\
-2.30 \text { it } \\
-1.96 \quad 1 \\
-2.16 \text { it }\end{array}$ & $\begin{array}{l}-19.59 \\
-13.99 \\
-20.59 \\
-18.02 \\
-25.88\end{array}$ \\
\hline $\begin{array}{c}3 \text { MONTHS } \\
\text { TOTAL } \\
\text { UK } \\
\text { WG } \\
\text { SH } \\
\text { JA }\end{array}$ & MMS & $1 / 83-10 / 84$ & $\begin{array}{r}187 \\
47 \\
47 \\
46 \\
47\end{array}$ & $\begin{array}{l}-4.01 \\
-4.09 \\
-3.65 \\
-3.49 \\
-4.82\end{array}$ & $\begin{array}{r}-10.98 \text { t1t } \\
-7.62 \text { 11t } \\
-5.39 \\
-3.51 \\
-7.57 \\
-711\end{array}$ & $\begin{array}{l}18.53 \\
18.38 \\
22.01 \\
22.23 \\
11.59\end{array}$ & $\begin{array}{l}7.72 \text { 111 } \\
3.95141 \\
4.73141 \\
4.78111 \\
2.4911\end{array}$ & $\begin{array}{r}14.51 \\
14.29 \\
18.36 \\
18.74 \\
6.75\end{array}$ \\
\hline $\begin{array}{l}\text { TOTAL } \\
\text { UR:. } \\
F R \\
W G \\
W G \\
S H \\
J A\end{array}$ & ECONOHIST & $6 / 81-12 / 85$ & $\begin{array}{l}190 \\
38 \\
38 \\
38 \\
38 \\
39\end{array}$ & $\begin{array}{l}-6.92 \\
-3.72 \\
-9.11 \\
-7.48 \\
-6.31 \\
-7.99\end{array}$ & $\begin{array}{l}-13.69 \mathrm{tt1} \\
-3.04 \mathrm{tt1} \\
-9.36 \mathrm{tt1} \\
-6.90 \mathrm{tt1} \\
-6.70 \mathrm{t11} \\
-6.37 \mathrm{t11}\end{array}$ & $\begin{array}{r}9.97 \\
10.09 \\
9.61 \\
11.02 \\
10.93 \\
9.29\end{array}$ & $\begin{array}{l}0.73 \\
1.61 \\
1.54 \\
1.76 \\
1.73 \\
1.33\end{array}$ & $\begin{array}{l}3.04 \\
6.37 \\
0.49 \\
3.55 \\
4.52 \\
0.30\end{array}$ \\
\hline 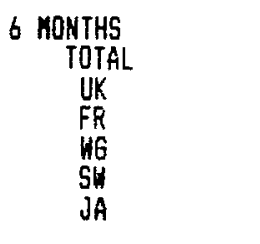 & ECONOHIST & $6 / 81-12 / 85$ & $\begin{array}{r}180 \\
36 \\
36 \\
36 \\
36 \\
36\end{array}$ & $\begin{array}{l}-7.22 \\
-4.21 \\
-8.94 \\
-8.20 \\
-6.40 \\
-8.34\end{array}$ & $\begin{array}{r}-25.94 \mathrm{t11} \\
-6.36 \mathrm{t11} \\
-14.19 \mathrm{t11} \\
-13.04 \mathrm{t11} \\
-9.98 \mathrm{t11} \\
-15.40 \mathrm{t11}\end{array}$ & $\begin{array}{l}11.70 \\
11.32 \\
11.08 \\
13.56 \\
12.77 \\
9.76\end{array}$ & $\begin{array}{l}0.95 \\
1.65 \\
1.62 \\
1.961 \\
1.861 \\
1.42\end{array}$ & $\begin{array}{l}4.48 \\
7.10 \\
2.15 \\
5.36 \\
6.37 \\
1.41\end{array}$ \\
\hline $\begin{array}{l}\text { TOTAL } \\
\text { Early Period } \\
\text { Later Period }\end{array}$ & AMEX & $\begin{array}{r}1 / 76-8 / 85 \\
1 / 76-12 / 78 \\
6 / 81-8 / 85\end{array}$ & $\begin{array}{l}51 \\
26 \\
25\end{array}$ & $\begin{array}{l}-1.81 \\
-0.14 \\
-3.54\end{array}$ & $\begin{array}{l}-3.19141 \\
-0.17 \\
-5.79141\end{array}$ & $\begin{array}{r}-2.11 \\
-7.78 \\
3.79\end{array}$ & $\begin{array}{l}-0.75 \\
-2.6511 \\
0.93\end{array}$ & $\begin{array}{r}-3.92 \\
-7.93 \\
0.26\end{array}$ \\
\hline $\begin{array}{c}12 \text { MONTHS } \\
\text { TOTAL } \\
\text { UK } \\
F R \\
\text { HG } \\
5 H \\
\text { JA }\end{array}$ & ECONONIST & $6 / 81-12 / 85$ & $\begin{array}{r}195 \\
31 \\
31 \\
31 \\
31 \\
31\end{array}$ & $\begin{array}{l}-5.93 \\
-3.34 \\
-7.70 \\
-7.00 \\
-4.60 \\
-6.33\end{array}$ & $\begin{array}{l}-28.13 \text { t1t } \\
-5.43 \text { 111 } \\
-17.86 \text { t11 } \\
-18.48 \text { t11 } \\
-10.69 \text { t11 } \\
-15.25\end{array}$ & $\begin{array}{l}14.83 \\
13.73 \\
15.10 \\
17.02 \\
16.73 \\
11.59\end{array}$ & $\begin{array}{l}7.46 \quad 114 \\
4.39114 \\
4.83 \text { 114 } \\
5.45 \quad 114 \\
5.35114 \\
3.71 \text { itt }\end{array}$ & $\begin{array}{r}9.00 \\
10.39 \\
7.20 \\
10.02 \\
12.13 \\
5.25\end{array}$ \\
\hline $\begin{array}{l}\text { TOTAL } \\
\text { Early Period } \\
\text { Later Period }\end{array}$ & AMEX & $\begin{array}{r}1 / 76-8 / 85 \\
1 / 76-1 / 79 \\
6 / 81-8 / 85\end{array}$ & $\begin{array}{l}46 \\
26 \\
20\end{array}$ & $\begin{array}{r}-0.67 \\
1.13 \\
-3.02\end{array}$ & $\begin{array}{r}-1.29 \\
1.71 \\
-6.12 \mathrm{it1}\end{array}$ & $\begin{array}{r}0.71 \\
-9.05 \\
13.40\end{array}$ & $\begin{array}{l}0.28 \\
-2.83 \mathrm{t4k} \\
12.52 \mathrm{tt1}\end{array}$ & $\begin{array}{r}0.04 \\
-7.92 \\
10.38\end{array}$ \\
\hline
\end{tabular}

Notes: Standard errars for the survey prediction errors are couputed using method of mogents. Amex standard errors, however, are calculated using the number of nonoverlappino observations and are thes upper bounds. Multi-country test statictics are f-tests of the fivpothesis that all

xeans are zera. 1 , tt, t\$, represent significance at the 10, 5 , and 1 percent levels, respectively. 
of this measurement error component in section 4. In the third place, the degree to which the surveys qualitatively corroborate one another is striking. For example, the risk premium in the Economist data (Chart 1) is negative during the entire sample, except for a short period from late 1984 until mid-1985. The MMS three-month sample (Chart 2) reports that the risk premium did not become positive until the last quarter of 1984, while MMS one-month data (Chart 3) shows the risk premium then remained positive until mid-1985. That the surveys agree on the nature and timing of major swings in the risk premium is some evidence that the particularities of each group of respondents do not influence the results.

We can test whether the data statistically reject the hypothesis that the means of the forward rate prediction errors are attributable entirely to the risk premia alone, assuming that the surveys measure expectations accurately. The tests for the significance of the mean survey prediction errors in Table 2 show that 27 out of 44 samples reject the hypothesis that the survey expectations are unbiased predictors of the future spot rate. This is a rejection of the equivalent hypothesis that the systematic component of the forward rate prediction errors is attributable entirely to the risk premium. We can also test whether the data statistically reject the hypothesis that the errors are attributable entirely to the existence of expectational errors. Table 2 shows that we can easily reject this hypothesis because the risk premium is significantly different from zero and of the opposite sign.

The survey data therefore suggest that an interpretation of the unconditional bias in the forward rate prediction errors that imposes rational expectations would lead to consistently incorrect conclusions with respect to the sign of the risk premium and the nature of its time-series variation. At the opposite extreme, the systematic portion of the errors could be interpreted solely as evi- 
FORWARD RATE ERRORS \& THE RISK PREMIUM

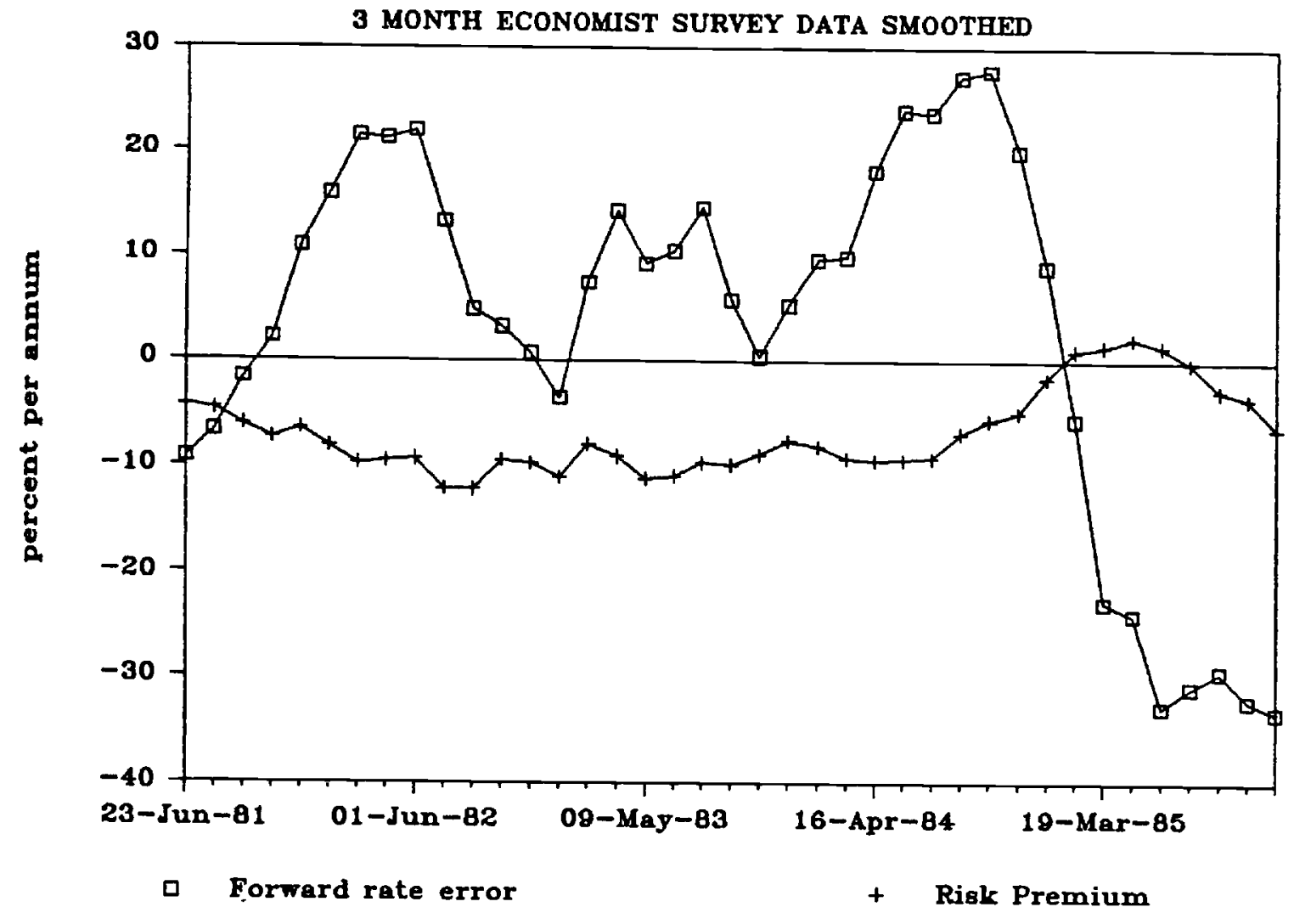

CHART 3

FORWARD RATE ERRORS \& THE RISK PREMIUM

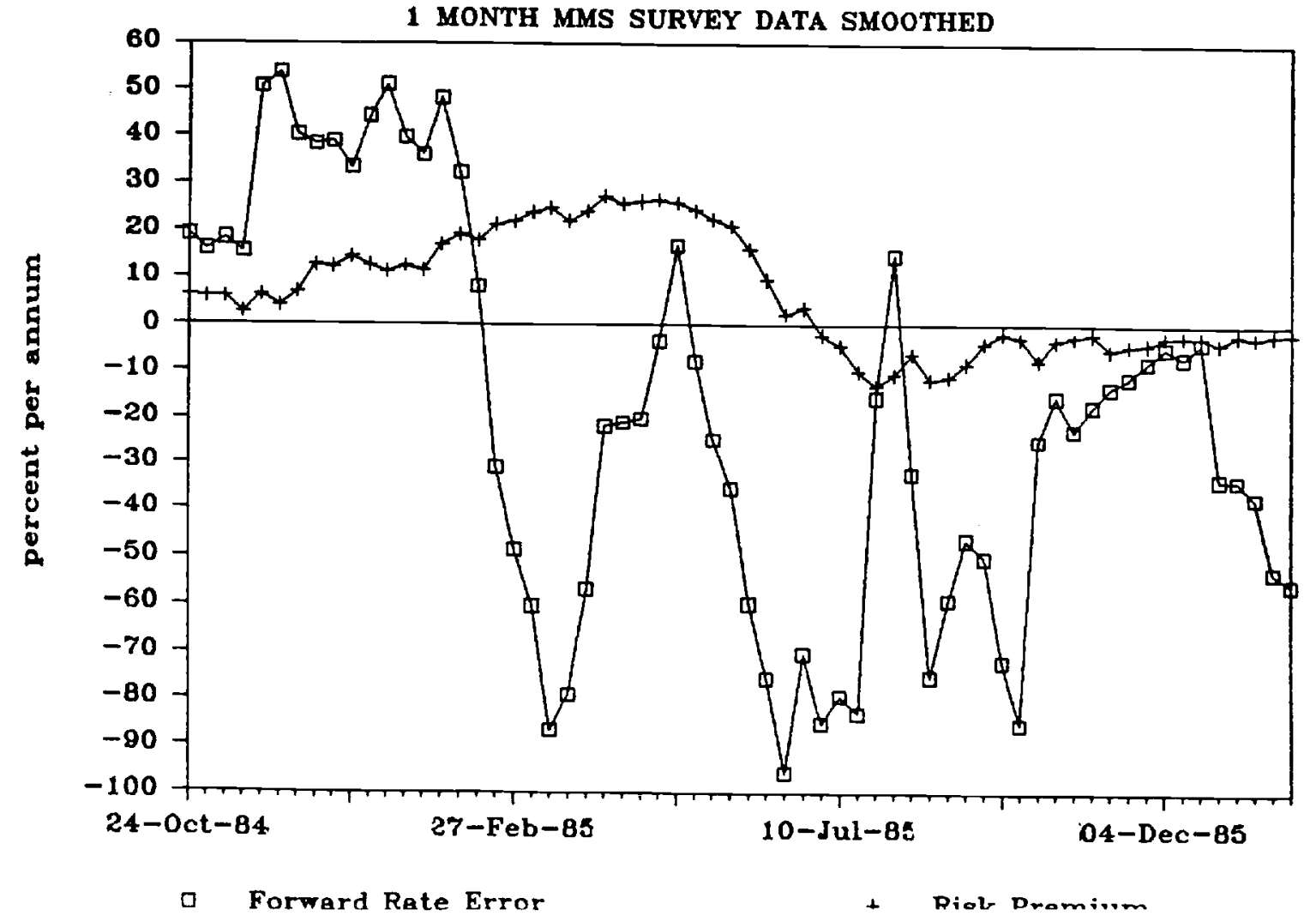


CHART 2

\section{FORWARD RATE ERRORS \& THE RISK PREMIUM}

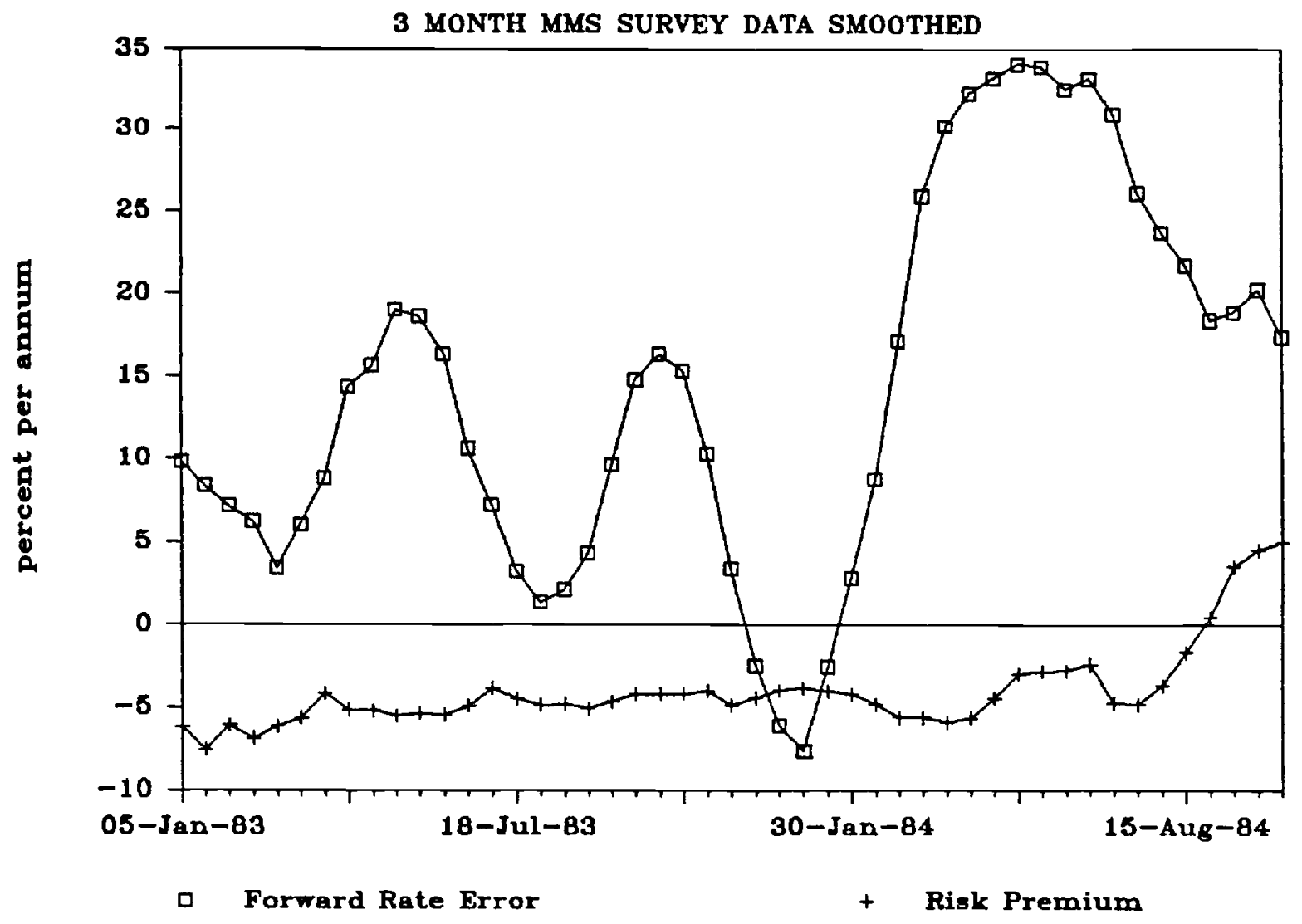

CHART 4

FORWARD RATE ERRORS \& THE RISK PREMIUM

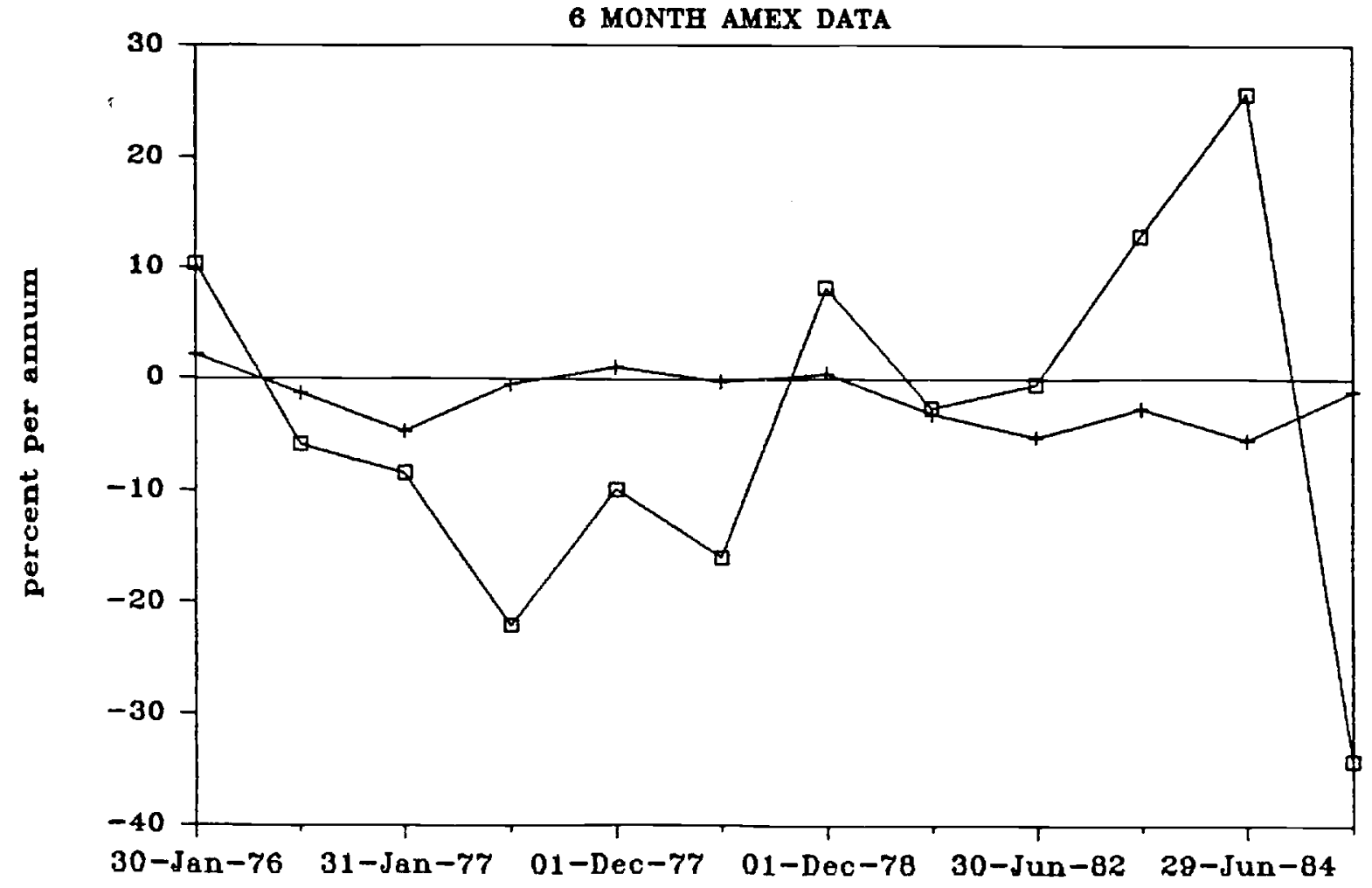


dence of a failure of rational expectations, but then the forward rate errors would offer no evidence at all regarding the substantial risk premia recorded in the survey data. Either interpretation, or any combination of the two, would miss the fact that the survey risk premium lies in the direction opposite to that indicated by the results in Table 1, that is, expectational errors are more than 100 percent responsible for the unconditional bias in the forward rate errors.

\subsection{Variability of the Risk Premium and Exchange Rate Expectations}

Survey data can also be used to shed some light on the relative volatility of expected depreciation and the risk premium. The recent papers by Fama (1984) and Hodrick and Srivastava (1986) argue that the risk premium is more variable than expected depreciation or, in the extreme formulation of Bilson (1985). that expected depreciation is zero. Table 3 shows the variance of expected changes in the spot rate and the variance of the risk premia, for each data set and broken down by currency. The magnitude of ex post exchange rate changes (column (1)) dwarfs that of the forward discount (column (2)).10 For example, the reported variance of annualized spot rate changes of 2 percent represents a standard deviation of about 14 percent. By comparison, the variance of expected depreciation is around .25 percent, a standard deviation of 5 percent.

The variance of expected depreciation is comparable in size to the variance of the risk premium, and is larger in 36 of the 40 samples calculated in Table 3. Thus "random walk" expectations are do not appear to be supported by the survey data. We test formally the Fama (1984) hypothesis that the variance of expected depreciation is less than the variance of the risk premium in section 4. Both are several times larger than the variance of the forward

10 This empirical regularity has often been noted; e.g., Mussa (1978). 
Table 3

COMPARISON OF VARIANCES OF EXPECTED DEPRECIATIOH

AHD THE RISK PREHIUH

(4) percent per annua)

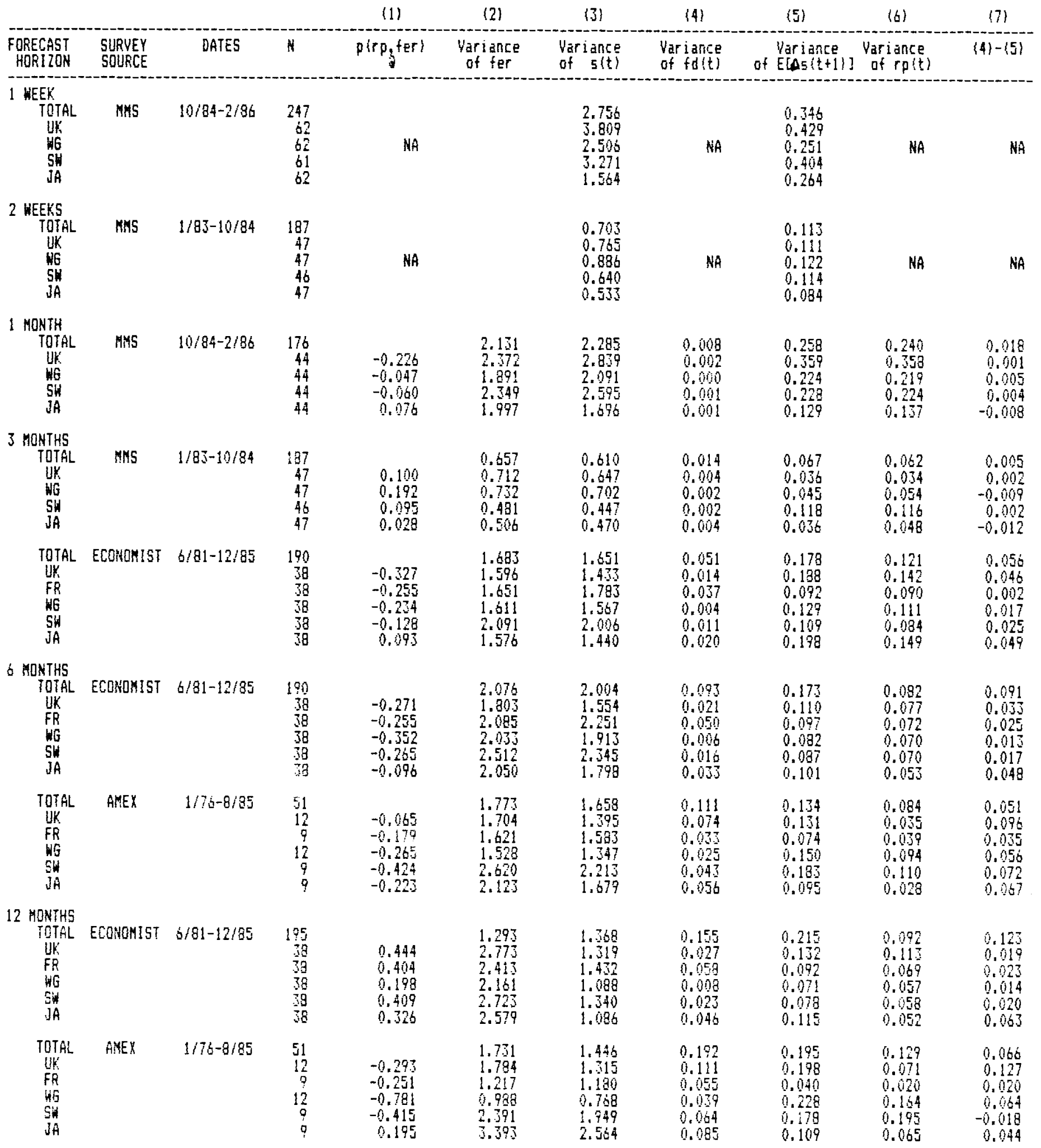

Notes: \& $p$ is the correlation coeficient and fer represents the forward

rate prediction error. For the sin-worth and twelve-month Economist and thelve-month fines data sets, coluens (1) and (2) contain 2,7 and 1 tewer obseryations tor eacti country, respectively, than indicated under coluan if. 
discount. Thus the relative stability of the forward discount masks greater variability in its two components, corroborating Fama's finding that the risk premium is negatively correlated with the expected change in the spot rate. ${ }^{11}$

Table 3 also has implications for tests of serial correlation in the forward rate errors, $f d_{t}^{k}-\Delta s_{t+k}$. Such tests have been performed by Hansen and Hodrick (1980), Dooley and Shafer (1982) and others. Under the assumption of rational expectations, any serially correlated component of the forward rate errors would be evidence of a time-varying risk premium. However, the small size of the variance of the risk premium compared to the variance of the forward rate errors (reported in columns (2) and (6) of Table 3, respectively). implies that even when the null hypothesis of no serial correlation fails because of the risk premium such tests will have low power. Using the assumption of rational expectations and equation (1), the autocorrelation coefficient of $f d_{t}^{k}-\Delta s_{t+k}$ converges in probability to:

$$
\frac{\operatorname{cov}\left(r p_{t}^{k}, r p_{t-k}^{k}\right)}{\operatorname{var}\left(f d_{t}^{k}-\Delta s_{t+k}\right)}=\rho \frac{\operatorname{var}\left(r p_{t}^{k}\right)}{\operatorname{var}\left(f d_{t}^{k}-\Delta s_{t+k}\right)}
$$

where $\rho$ is the probability limit of the corresponding autocorrelation coefficient of the risk premium. Table 3 suggests that ratio of the variance of the risk premium to that of the forward rate errors on the righthand-side of equation (1.) has an upper bound of 0.1.12 Thus, even if the the risk premium follows a random walk, so that $\rho=1$, this ratio implies that the upper bound for the portion of the autocorrelation coefficient of the prediction errors attributable to

11 This correlation is, however, biased downward by any measurement error that might be present in the surveys. If such error is purely random, then the corariance of expected depreciation and the risk premium mag be written as $\operatorname{cov}\left(\Delta \mathbf{s}_{t+k} \mathbf{r P}_{\mathrm{t}}\right)-\mathrm{var}\left(\xi_{t+k}\right)$, where $\Delta \Delta_{t+k}$ and $\mathbf{r P t}_{\mathrm{t}}$ are the "true" values of expected depreciation and of the risk premium, respectively, and $\xi_{t+k}$ is the measurement error component of the survey.

18 In the Economist data for example, the autocorrelation coefficient of the survey risk premium, $\rho$, is considerably less than one: for the three-, six-and twelve-month data sets $\rho$ equals $.18, .23$ and .08 , respectively. 
the risk premium is only 0.1 .

\section{USING THE SURVEY DATA IN THE FORTARD RATE UNBIASEDNESS REGRESSION}

In tests of forward market unbiasedness, attention has focused on the optimal weights placed on the forward rate versus the contemporaneous spot rate in predicting the future spot rate. The equation most commonly used is a regression of the future change in the spot rate on the forward discount:

$$
\Delta s_{t+k}=\alpha+\beta f d_{t}^{k}+\varepsilon_{t+k}^{k}
$$

where the null hypothesis is that the weight on the forward rate is one and the constant term is zero, i.e., $\beta=1$ and $\alpha=0$. In other words, the realized spot rate is equal to the forward rate plus a purely random error term. A second but equivalent specification is a regression of the forward rate prediction error on the forward discount:

$$
f_{t}^{k}-s_{t+k}=\alpha_{1}+\beta_{1} f d_{t}^{k}+\varepsilon_{1, t+k}^{k}
$$

where $\alpha_{1}=-\alpha$ and $\beta_{1}=1-\beta$. The null hypothesis is now that $\alpha_{1}=\beta_{1}=0$ : the left-hand-side variable is purely random.

Most tests of equation (2) have rejected the null hypothesis, finding $\beta$ to be significantly less than one. The range of point estimates has been wide, from about -2.8 to 0.8 . Coefficients that are positive, but less than one, imply that the optimal predictor of the spot rate puts positive weight on both the forward rate and the contemporaneous spot rate. A coefficient of zero is the random walk hypothesis: the forward discount is of no help in forecasting future spot rate changes. ${ }^{13}$ Least appealing, but nevertheless not unusual, are findings of

15 Findings of this kind are not limited to investigations of foreign exchange markets. In their study of the expectations hypothesis of the term structure, for example, Shiller. Campbell and Schoenholtz (1983) conclude that changes in the premium paid on longerterm bills over short-term bills are useless for predicting future changes in short-term in-
terest rates. 
significant negative coefficients, which indicate that the spot rate tends to move in the direction opposite to that predicted by the forward discount.

As in the previous section, tests of equation (2) are joint tests of rational expectations and no exchange risk premium. Without other information, however, researchers have been forced to focus on one alternative hypothesis at the expense of the other. For example, one could ignore the risk premium and interpret the forward rate as representing investors' expectations. In this context, Bilson (1981b) proposed that the alternative of $\beta$ less than one be termed "excessive speculation", because it would imply that investors could do better on average if they were to reduce fractionally their forecasts of exchange rate changes, and that the alternative of $\boldsymbol{\beta}$ greater than one be termed "insufficient speculation", because it would imply that investors could do better if they were to raise multiplicatively the magnitude of their forecasts of exchange rate changes.

The most popular alternative hypothesis in regressions of equations like (2), however, is that domestic and foreign securities are imperfect substitutes because of risk. As we have already mentioned, Fama (1984), Hodrick and Srivastava (1986) and Bilson (1985) argue that coefficients close to zero in such regressions can be viewed as evidence of a risk premium that is more variable than are expectations. By taking probability limits, the slope coefficient $\beta$ in equation ( 2 ) can be rewritten as:

$$
\begin{aligned}
\beta & =\frac{\operatorname{cov}\left(\Delta s_{t+k}, f d_{t}^{k}\right)}{\operatorname{var}\left(f d_{t}^{k}\right)}=\frac{\operatorname{cov}\left(\Delta s_{t+k}^{*}, f d_{t}^{k}\right)}{\operatorname{var}\left(\Delta s_{t+k}^{k}\right)+2 \operatorname{cov}\left(\Delta s_{t+k}^{k}, r p_{t}^{k}\right)+\operatorname{var}\left(r p_{t}^{k}\right)} \\
& =\frac{\operatorname{var}\left(\Delta s_{t+k}^{k}\right)+\operatorname{cov}\left(\Delta s_{t+k}^{e}, r p_{t}^{k}\right)}{\operatorname{var}\left(\Delta s_{t+k}^{k}\right)+2 \operatorname{cov}\left(\Delta s_{t+k}^{k}, r p_{t}^{k}\right)+\operatorname{var}\left(r p_{t}^{k}\right)}
\end{aligned}
$$

where the second equality follows from assuming rational expectations. If $\beta<\not / 2$ 
as is usually found, it follows that $\operatorname{var}\left(r p_{t}^{k}\right)>\operatorname{var}\left(\Delta s_{t+k}^{b}\right)$. Accordingly, Bilson (1985 p. 63) interprets the accumulated results of such regressions as evidence that "most of the variation in the [forward] premium reflects variation in the risk premium rather than variation in the expected rate of appreciation." Indeed, the growing body of evidence that $\beta$ is insignificantly different from zero does not permit one to reject the extreme view that expectations are totally unrelated to the forward rate, in other words, that all variation in the forward discount is attributable solely to variation in the risk premium.

\subsection{Econometric Issues}

Before turning to our own estimates of equation (2), we pause briefly to mention several important econometric issues.

Estimation of equation (2) (and most of the equations we estimate later), is performed using OLS. We stack different countries, and in some cases different forecast horizons, into a single equation. The complicated correlation pattern of the residuals, however, renders the OLS standard errors incorrect in finite samples. Several types of correlation are present.

First, there is serial correlation induced by a sampling interval shorter than the corresponding forecast horizon (up to eight times). This is the usual case in which overlapping obs vations imply that, under the null hypothesis, the error term is a moving average process of an order equal to the frequency of sampling interval divided by the frequency of the horizon, minus one. Hansen and Hodrick (1980) propose using a method of moments (MoM) estimator for the standard errors in precisely the application studied here.

Second, in order to take advantage of the fact that the surveys covered four or five currencies simultaneously, we pooled the regressions across countries. This type of pooling induces contemporaneous correlation in the residu- 
als. ${ }^{14}$ Normally, Seemingly Unrelated Regressions should be used to exploit this correlation efficiently. We use SUR later; here, however, the serial correlation induced by overlapping observations makes SUR inconsistent.

The basic model may be written as:

$$
y_{t, i}^{k}=x_{t-k, i}^{k} \beta+\nu_{t, i}^{k}
$$

where $k$ is the number of periods in the forecast horizon and $i$ indexes the currency. We account for the two types of correlation in the residuals with a MoM estimate of the covariance matrix of $\tilde{\beta}$ :

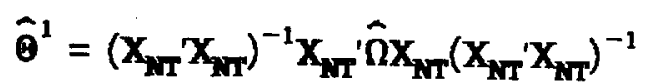

where $\mathbf{X}_{\mathbf{M r}}$ is the matrix of regressors of size N (countries) times T (time). The $(i, j)$ th element of the unrestricted covariance matrix, $\hat{\Omega}$ is:

$$
\begin{aligned}
\hat{\omega}(i, j) & =\frac{1}{N T-k} \sum_{i=0 t=k+1}^{N-1} \sum_{t}^{T} \hat{\nu}_{t+l T} \hat{\nu}_{t-k+l T} \text { for } m T-r \leq k \leq m T+r ; m=0, \ldots, N-1 \\
& =0 \quad \text { otherwise. }
\end{aligned}
$$

where $r$ is the order of the MA process, $\hat{\nu}_{t+l T}$ is the OLS residual, and $k=|i-j|$. In some cases, this unrestricted estimate of $\Omega$ uses well over 100 degrees of freedom. ${ }^{15}$ We therefore estimated a restricted covariance matrix, $\tilde{\Omega}$ with typical element:

$$
\begin{aligned}
& \tilde{\omega}(t+l T, t-k+p T)=\frac{1}{N-1} \sum_{l=0}^{N} \hat{\omega}(t+l T, t-k+p T) \text { if } \lambda=p \text { and }-r \leq k \leq r \\
& =\frac{2}{N(N-1)} \sum_{p=0}^{N-1 N-1} \sum_{l=0} \hat{\omega}(t+l t, t-k+p T) \text { if } \lambda \neq p \text { and }-r \leq k \leq r
\end{aligned}
$$

\footnotetext{
14 Each currency in our pooled regressions was given its own constant term. This modeling strategy seemed most reasonable in view of the differences across currencies in the magnitudes of both ex post spot rate changes and the forward discount (see Table 1).

15 The number of independent parameters in the covariance matrix does not affect the esymptotic covariance, as long as these parameters are estimated consistently (see Hansen
} 
$=0$ otherwise.

These restrictions have the effect of averaging the own-currency and crosscurrency autocorrelation functions of the OLS residuals, respectively, bringing the number of independent covariance parameters down to $2 r$.

Tests of forward discount unbiasedness also provide an opportunity to aggregate across different forecast horizons (though we are unaware of anyone who has done this, even with the standard forward discount data), adding a third pattern of correlation in the residuals. Such stacking seems appropriate in this case because we wish to study the predictive power of the forward discount generally, rather than at any particular time horizon. Moreover, a MoM estimator which incorporates several forecast horizons has appeal beyond the particular application studied here because it is computationally simpler than competing techniques and at the same time can be more efficient than single k-step-ahead forecasting equations estimated with MoM.

To demonstrate the precise nature of the correlation induced by such aggregation, consider the stochastic process, $Y_{t}$, which is stationary and ergodic in first differences and has finite second moments. We denote the $k$ period change in $y$ from period $t-k$ to $t$ as $y_{t}^{k}$, and the $h$ period change as $n-1$

$y_{t}^{h}=\sum y_{t-i k}^{k}$, where $h=n k$ for any positive integer n. ${ }^{16}$ We then define the $i=0$

innovations, $\nu_{t}^{k}$ and $\nu_{t}^{h}$ as:

$$
\nu_{t}^{k}=y_{t}^{k}-E\left(y_{t}^{k} \mid \varphi_{t-k}\right)
$$

(1882)). Nevertheless, one suspects that the small-sample properties of the MoM estimator worsen as the number of nuisance parameters to be estimated increases.

18 The following example can easily be generalized to allow $h$ and $k$ to be any positive integers. It is also possible to combine in a similar fashion more than two different forecast horizons. Indeed, we combine three horizons in the Economist data estimates in the regressions below. Because these extensions yield no additional insights and come at the cost of more complicated algebra, however, we retain the simple example above. 


$$
v_{t}^{n}=y_{t}^{n}-E\left(y_{t}^{h} \mid \varphi_{t-h}\right)
$$

where $\varphi_{t}$ includes present and lagged values of the vector of right-hand-side variables, $x_{t}^{k}$. These facts allow us to write the covariance matrix of the innovations as:

$$
\Sigma=E\left[\left[\begin{array}{l}
\nu_{t}^{k} \\
\nu_{t}^{h}
\end{array}\right]\left[\nu_{t}^{k_{1}} \nu_{t}^{h_{1}}\right]\right]=\left[\begin{array}{cc}
\Delta^{k} & \Delta^{h k} \\
\Delta^{h k}, & \Delta^{h}
\end{array}\right]
$$

where the $(i, j)$ th element of each submatrix of $\Sigma$ is equal to the corresponding autocovariance function, evaluated at $q=i-j$ :

$$
\begin{aligned}
\Delta_{i, j}^{k}=E\left(\nu_{t}^{k} \nu_{t+q}^{k}\right) & =\lambda_{q}^{k} \text { if }|q|<k \\
& =0 \text { otherwise. } \\
\Delta_{i, j}^{h}=E\left(\nu_{t}^{h} \nu_{t+q}^{h}\right) & =\lambda_{q}^{h} \text { if }|q|<h \\
& =0 \text { otherwise. } \\
\Delta_{i, j}^{h k}=E\left(\nu_{t}^{k} \nu_{t+q}^{h}\right) & =\lambda_{q}^{h k} \text { if } 0 \leq q<k \\
=E\left(\nu_{t}^{k} \nu_{t+q}^{h}\right) & =\lambda_{q}^{h k} \text { if }-h<q<0 \\
& =0 \text { otherwise. }
\end{aligned}
$$

In this context consider the aggregated model:

$$
\mathbf{y}_{t}=\mathbf{x}_{t} \beta+\nu_{t}
$$

where $y_{t}^{\prime} \equiv\left[\begin{array}{ll}y_{t+k}^{k} & y_{t+h}^{h}{ }^{\prime}\end{array}\right], x_{t}^{\prime} \equiv\left[\begin{array}{ll}x_{t}^{k_{1}} & x_{t}^{h^{\prime}}\end{array}\right]$ and $v_{t}^{\prime} \equiv\left[\begin{array}{ll}v_{t+k}^{k} & \nu_{t+h}^{h}\end{array}\right]$. The OLS estimate of $\beta$ then has the usual MoM estimate of the sample covariance matrix:

$$
\hat{\theta}^{z}=\left(x_{2 N T} x_{2 N T}\right)^{-1} x_{2 N T} \cdot \hat{\Sigma} x_{2 N T}\left(x_{2 N T} x_{2 N T}\right)^{-1}
$$

where $\hat{\Sigma}$ is a consistent estimate of $\Sigma$, and is formed by using the OLS residuals to estimate the autocovariance and crosscovariance functions in equations (9) and $(10)$.

One might think that by stacking forecast horizons, as we do in equation (11), greater asymptotic efficiency always results than if only the shorter-term 
forecasts are used, in other words, that $\hat{\theta}^{1}-\hat{\theta}^{2}$ is positive semidefinite. After all, the sample size has doubled, and the only additional estimates we require are nuisance parameters of the covariance matrix. This intuition would be correct for asymptotically efficient estimation strategies, such as maximum likelihood. But because OLS weights each observation equally, the MoM covariance estimates reffect the average precision of the data. It follows that if the longer-term forecasts are sufficiently imprecise relative to the shorter-term forecasts, the precision of the estimate of $\beta$ drops: we could actually lose efficiency by adding more data. In the appendix we demonstrate this potential loss in asymptotic efficiency, and show how it is related to the disparity in forecast horizons. Efficiency is most likely to increase if the longer-term forecast horizon is a relatively small multiple of the shorter-term horizon. Indeed, in the forthcoming regressions we find a marked increase in precision from stacking across forecast horizons when $r=2$ (in the Economist and Amex samples), but little or no increase in precision when $r=4$ or 6 (in the MMS samples).

Finally, the above MoM estimates of the covariance matrix need not be positive definite in small samples. Newey and West (1985) offer a corrected estimate of the covariance matrix that discounts the jth order autocovariance by $1-(j /(m+1))$. making the covariance matrix positive definite in finite sample. Nevertheless, for any given sample size, there remains the question of how small $m$ must be to guarantee positive definiteness. In the upcoming regressions we tried $m=r$ (which Newey and West themselves suggest) and $m=2 r$; we report standard errors using the latter value of $m$ because they were consistently larger than those using the former. ${ }^{17}$

17 For the two aggregated MMS data sets in Table 8 below, a value of $m=r$ was used after finding that $m=2 r$ resulted in a nonpositive semi-definite covariance matrix. This correction reduced the standard errors in these two regressions by an average of only 3 percent. 


\subsection{Results}

Table 4 presents the standard forward discount unbiasedness regressions (equation (2)) for our sample periods. ${ }^{18}$ Most of the coefficients fall into the range reported by previous studies. Note that in the Economist and Amex data sets, in which forecasts horizons were stacked, the standard errors fell in the aggregated regressions by 14 and 31 percent, respectively, in comparison with regressions that used the shorter-term predictions alone. In terms of the point estimates, all but one of the data sets indicate that the optimal predictor of the future spot rate places negative weight on the forward rate, and more than half of the coefficients are significantly less than zero. There is ample evidence to reject unbiasedness. In the two MMS data sets, which cover shorter sample periods of 14 and 21 months, respectively, the coefficients have unusually large absolute values, lending support to the observation by Gregory and McCurdy (1984) that the regression relation in equation (2) may be unstable. The F-tests also indicate that the unbiasedness hypothesis fails in most of the data sets.

At this point, we could interpret the results as reflecting systematic prediction errors. Under this interpretation, it follows that agents would do better by placing more weight on the contemporaneous spot rate and less weight on other factors in forming predictions of the future spot rate, the view discussed by Bilson (1981b). On the other hand, we could interpret the results as evidence of a time-varying risk premium. Then the conclusions would be that changes in expected depreciation are not correlated (or are negatively correlated) with changes in the forward discount and, from equation (3), that the variance of the risk premium is greater than the variance of expected depreciation.

18 Regressions were estimated with dummies for each country, which we do not report to save space. For the regressions which pool over different forecast horizons (marked Economist Data and Amex Data), each country was allowed its own constant term for every
forecast horizon. 
TABLE 4

TESTS OF FORHARD DISCOUNT UNRIASEDMESS

QLS Regressions of $\Delta s(t+1)$ on $f d(t)$

\begin{tabular}{|c|c|c|c|c|c|c|c|c|}
\hline Data Set & Dates & $\hat{E}$ & $t: \hat{E}=0$ & $t: \hat{E}=1$ & $F^{2}$ & DF & $\begin{array}{l}F \text { test } \\
A=0, \quad B=1\end{array}$ & Prob $>\mathrm{F}$ \\
\hline Economist bata & $6 / 81-12 / 85$ & $\begin{array}{l}-0.5624 \\
11.017 !)\end{array}$ & -0.56 & -1.54 & 0.16 & 509 & 2.12 & 0.007 \\
\hline Econ 3 Month & $5 / 81-12 / 85$ & $\begin{array}{l}-1.2090 \\
(1.1596)\end{array}$ & -1.04 & -1.91 & 0.01 & 184 & 1.29 & 0.262 \\
\hline Econ b Month & $6 / 81-12 / 85$ & $\begin{array}{l}-1.9819 \\
(1.4445)\end{array}$ & -1.37 & -2.0611 & 0.07 & 174 & 1.47 & 0.191 \\
\hline Econ 12 Month & $6 / 81-12 / 85$ & $\begin{array}{l}0.2892 \\
(1.2733)\end{array}$ & 0.23 & -0.56 & 0.27 & 149 & 3.23 & $0.00 \mathrm{E}$ \\
\hline
\end{tabular}

MS I Honth

MS 3 Honth

AMEY Data

MEY o ononth

ANEX 12 Wonth
$10 / 54-2 / 96$

$1 / 83-10 / 84$$$
0.21
$$$$
171
$$$$
2.67
$$$$
0.024
$$$$
\text { (b. } 0000)
$$

$1 / 76-7 / 95$

$$
\begin{aligned}
& -2.2107 \\
& (0.9623)
\end{aligned}
$$$$
-2.30
$$$$
14
$$$$
-3.34 \text { th }
$$$$
0.23
$$$$
1 / 76-7195
$$$$
-2,418
$$$$
\text { (1.2608) }
$$$$
-1.921
$$$$
-2.71
$$$$
0.26
$$$$
21377
$$$$
\text { (1.0549) }
$$

$-2.1377$

$-2.0$.

14 $-2.97 \$ 1$

411

0.21

40

Eb

2.60

0.007

Hotes: Hethod of Monents standard errors are in pafentheses. Fepresents significance at the 10\% level, and tot renresent significance at the s\% and 1\% levelso respectively. 


\subsection{Decomposition of the Forward Discount Bias Coefficient}

The survey data, however, let us go a step further with the results of Table 4: we can now allocate part of the deviation from the null hypothesis of $\beta=1$ to each of the alternatives: failure of rationality and the presence of a risk premium. Using the fact that the (log) forward discount can be written as the sum of expected depreciation plus the risk premium,

$$
f d_{t}^{k}=\Delta s_{t+k}^{*}+r p_{t}^{k}
$$

we can decompose the probability limit of the coefficient $\beta$ in equation ( 2 ) into:

$$
\beta=\frac{\operatorname{cov}\left(\eta_{t+k}^{k}, f d_{t}^{k}\right)+\operatorname{cov}\left(\Delta s_{t+k}^{k}, f d_{t}^{k}\right)}{\operatorname{var}\left(f d_{t}^{k}\right)}
$$

where $\eta_{t+k}^{k}$ is the expectational prediction error defined in equation (1). With a little algebra, $\beta$ can then be written as equal to 1 (the null hypothesis) minus a term arising from any failure of rational expectations, minus another term arising from the risk premium:

$$
\beta=1-\beta_{r e}-\beta_{\text {pp }}
$$

where

$$
\begin{aligned}
& \beta_{r t}=\frac{\operatorname{cov}\left(\eta_{t+k}^{k}, f d_{t}^{k}\right)}{\operatorname{var}\left(f d_{t}^{k}\right)} \\
& \beta_{r p}=\frac{\operatorname{var}\left(r p_{t}^{k}\right)+\operatorname{cov}\left(\Delta s_{t+k}^{k}, r p_{t}^{k}\right)}{\operatorname{var}\left(f d_{t}^{k}\right)} .
\end{aligned}
$$

With the help of the survey data, both terms are observable. By inspection, $\beta_{r a}=0$ if there are no systematic prediction errors in the sample, and $\beta_{\boldsymbol{p}}=0$ if there is no risk premium (or, somewhat more weakly, if the risk premium is uncorrelated with the forward discount). 
The results of the decomposition are reported in Table 5a. First, $\beta_{r e}$ is very large in size when compared to $\beta_{T p}$, often by more than an order of magnitude. In all of the regressions, the lion's share of the deviation from the null hypothesis consists of systematic expectational errors. For example, in the Economist data, our largest survey sample with 525 observations, $\beta_{r e}=1.49$ and $\beta_{r p}=0.08$. Second, while $\beta_{r e}$ is greater than zero in all cases, $\beta_{r p}$ is sometimes negative, implying in equation (14) that the effect of the survey risk premium is to push the estimate of the standard coefficient $\beta$ in the direction above one. In these cases, the risk premia do not explain a positive share of the forward discount's bias. The positive values for $\beta_{r e}$, on the other hand, suggest the possibility that investors tended to overreact to other information, in the sense that respondents might have improved their forecasting by placing more weight on the contemporaneous spot rate and less weight on the forward rate. Third, to the extent that the surveys are from different sources and cover different periods of time, they provide independent information, rendering their agreement on the relative importance and sign of the expectational errors all the more forceful. To check if the level of aggregation in Table 5a is hiding important diversity across currencies, Table $5 \mathrm{~b}$ reports the decomposition for each currency in every data set. Here the results are the same: expectational errors are consistently large and positive, and the risk premium appears to explain no positive portion of the bias.

While the qualitative results above are of interest, we would like to know whether they are statistically significant, whether we can formally reject the two obvious polar hypotheses: a) that the results in Table 4 are attributable entirely to expectational errors; and b) that they are attributable entirely to the presence of the risk premium in the survey data. We test these hypotheses in turn in the following sections. 
TADLE 5 a

COMFONENTS OF THE FAILURE OF THE UHBIASEDNESS HYFDTHESIS

IN FEGRESSIONS IF $\triangle S(t+1)$ ON FO(t)

\section{Failure of Rationa! Expectations}

(1)

Data Set
Econonist Data 3 Month
Econ 6 Month
MMS 12 Month
MMS 3 Month
AMEX Data
AMEX 6 Month

AMEX 12 Month

$$
10 / 84-2 / 86 \quad 176
$$

$1 / 83-10 / 84$

189

$1 / 76-7 / 85 \quad 97$

$1176-7 / 85 \quad 51$

$1 / 76-7 / 84 \quad 46$
Existence of

Risk Prenium

(2)
Inplied Regression Coefficient $1-(1)-(2)$

\begin{tabular}{ccccc}
$\begin{array}{c}\text { Approxinate } \\
\text { Dates }\end{array}$ & $N$ & $\hat{B}_{r i}$ & $\hat{B}_{\text {if }}$ & $\hat{B}$ \\
\hline $6 / 81-12 / 85$ & 525 & 1.49 & 0.08 & -0.57 \\
$6 / 81-12 / 85$ & 190 & 2.51 & -0.30 & -1.21 \\
$6 / 81-12 / 85$ & 180 & 2.99 & 0.00 & -1.98 \\
$6 / 81-12 / 85$ & 155 & 0.52 & 0.19 & 0.29
\end{tabular}


TARLE 5b

COMPONENTS OF THE FAILURE OF THE IJNBIASEDNESE HYPDTHESIS

IN REGRESSIONS OF $\triangle S(t+1)$ ON FD(t)

\section{Failure of Rational \\ Expectations}

(1)

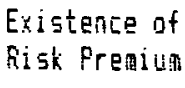

(2)
Inplized

Regression

Coofficient

$1-(1)-(2)$

\begin{tabular}{|c|c|c|c|c|c|}
\hline Data Set & $\begin{array}{c}\text { Approzinate } \\
\text { Dates }\end{array}$ & N & $\hat{B}_{r e}$ & $\hat{B}_{r_{p}}$ & $\hat{B}$ \\
\hline ECON 3 MONTH & $6 / 81-12 / 85$ & 190 & 2.51 & -0.30 & -1.21 \\
\hline uk & & 38 & 7.31 & -1.11 & -5.20 \\
\hline$F R$ & & 38 & -1.75 & 0.47 & 2.28 \\
\hline WG & & 38 & 7.69 & -1.64 & -5.05 \\
\hline $5 \mathrm{H}$ & & 38 & 5.03 & -0.63 & -3.40 \\
\hline TA & & 38 & 4.66 & -0.73 & -2.93 \\
\hline ECON \& MONTH & $6 / 81-12 / 35$ & 180 & 2.99 & 0.60 & -1.98 \\
\hline 比 & & 36 & 7.04 & -0.17 & -5.87 \\
\hline$F R$ & & 36 & -1.31 & 0.21 & 2.10 \\
\hline$\$ 6$ & & 36 & 10.16 & -0.38 & -8.77 \\
\hline 54 & & 36 & 5.75 & -0.01 & -4.74 \\
\hline JA & & 36 & 4.69 & -0.18 & -3.51 \\
\hline ECON 12 MONTH & $6 / 81-12 / 85$ & 155 & 0.52 & 0.19 & 0.29 \\
\hline UK & & 31 & 1.87 & 0.93 & -1.79 \\
\hline$F R$ & & 31 & -1.45 & 0.16 & 2.29 \\
\hline N6 & & 31 & -0.13 & 0.16 & 0.76 \\
\hline $5 n$ & & 31 & 0.96 & 0.25 & -0.21 \\
\hline JA & & 3 & 3.09 & -0.04 & -2.05 \\
\hline MMS 1 HONTH & $10 / 94-2 / 86$ & 176 & 15.37 & 0.16 & -14.55 \\
\hline $\mathrm{UK}$ & & 44 & 21.23 & 0.06 & -20.28 \\
\hline Ho & & 44 & 10.34 & -8.95 & -0.39 \\
\hline SH & & 44 & 13.15 & -2.39 & -9.26 \\
\hline IA & & 44 & 4.58 & 7.10 & -10.68 \\
\hline MMS I MDNTH & $1 / 83-10 / 84$ & 108 & 6.07 & 1.18 & 6.25 \\
\hline$U R$ & & 47 & 7.90 & 0.27 & -7.16 \\
\hline WG & & 47 & 4.96 & 2.52 & -6.48 \\
\hline 54 & & 47 & 7.90 & 0.09 & -6.95 \\
\hline$J A$ & & 47 & 3.43 & 2.14 & -4.57 \\
\hline AHEX \& MONTH & $1 / 76-7 / 55$ & $5 !$ & 3.6 .3 & -3.22 & -2.42 \\
\hline u & & 12 & 2.76 & -0.15 & -1.60 \\
\hline$E R$ & & 9 & 1.09 & $-0,03$ & -0.06 \\
\hline 46 & & 12 & 4.78 & $-0.6 j$ & -3.15 \\
\hline 5 & & 9 & 5.5 & -0.35 & -4.20 \\
\hline IA & & 9 & 4.53 & -0.10 & -3.48 \\
\hline AME: $12 \mathrm{MONTH}$ & $1 / 1 / 5-7 / 84$ & 46 & 3.11 & 0.03 & 2.14 \\
\hline$\underline{k}$ & & $\because !$ & 2.5 & -0.07 & -1.45 \\
\hline$F_{n}$ & & 8 & 0.43 & 0.32 & 0.20 \\
\hline 16 & & 11 & 3.53 & -0.40 & -2.15 \\
\hline 51 & & $\Xi$ & 3.99 & 0.38 & -3.77 \\
\hline $7 \mathrm{~A}$ & & 9 & 5.36 & 0.12 & -4.49 \\
\hline
\end{tabular}




\section{A Direct Test of Perfect Substitutability}

We consider first a test of whether the bias introduced by the risk premium. $\beta_{r p}$, is statistically significant. The most direct test is a regression of the survey expected depreciation against the forward discount:

$$
\Delta s_{t+k}^{*}=\alpha_{2}+\beta_{2} f d_{t}^{k}+\varepsilon_{2, t}
$$

where the null hypothesis is that no risk premium separates the two, $\alpha_{2}=0$ and $\beta_{2}=1$. Strictly speaking, the expected future spot rate exactly equals the forward rate if assets are perfect substitutes, so that we should interpret the regression error $\varepsilon_{2, t}$ as measurement error in the surveys. Thus, $\Delta s_{t+k}^{e}=\Delta \bar{s}_{t+k}^{e}+\varepsilon_{2, t}$, where $\Delta \bar{s}_{t+k}^{e}$ is the unobservable "true" market expected change in the spot rate. Note that if the null hypothesis holds, we can use the $R^{2}$ from equation (17) to obtain an estimate of the relative importance of the measurement error component in the survey data. ${ }^{18}$

To see that a test of $\beta_{2}=1$ is equivalent to a test of $\beta_{r p}=0$, note that the OLS estimate of $\beta_{2}$ converges in probability to:

$$
\begin{aligned}
\beta_{2} & =1-\frac{\operatorname{var}\left(\overline{\mathbf{r} \mathbf{p}_{\mathbf{t}}}\right)+\operatorname{cov}\left(\Delta \overline{\mathbf{s}_{\mathbf{t}+\mathbf{k}} \cdot \overline{\mathbf{r} \mathbf{p}_{\mathbf{t}}}}\right)}{\operatorname{var}\left(f d_{t}^{k}\right)} \\
& =1-\beta_{\mathbf{r p}}
\end{aligned}
$$

where $\overrightarrow{\mathbf{r P}_{\mathbf{t}}}$ is the survey risk premium less any measurement error, i.e., the "true" market risk premium, $f d_{t}^{k}-\Delta \mathbf{s}_{t+k}^{e}$ Equation (17) may also be used to test formally the Fama (1984) hypothesis regarding the size of the variance of expected depreciation relative to the variance of the risk premium. A little algebra yields:

19 Note also that in a test of equation (17) using the survey data, the properties of the error term, $\varepsilon_{2, t}$, will be invariant to any "peso problems," which affect instead the ex post distribution of actual spot rate changes. 


$$
\boldsymbol{\beta}_{2}=\frac{\operatorname{var}\left(\Delta \overrightarrow{\mathbf{s}}_{\mathbf{t}+\mathbf{k}}\right)-\operatorname{var}\left(\overrightarrow{\mathbf{r} \mathbf{p}_{\mathbf{t}}}\right)}{\operatorname{var}\left(f d_{t}^{k}\right)}+y_{2}
$$

Equation (19) says that if $\beta_{2}$ is significantly greater than ${ }_{2}$, the variance of expected depreciation exceeds that of the risk premium. The qualitative finding in Table 3, column (6), that the variance of expected depreciation is the greater can thus be tested formally. Although measurement error in the survey data would tend to overstate both of these variances, it does not affect the estimate of their difference (equation (19)). This point is evident from equation (17), in which the measurement error $\varepsilon_{2, t}$ is conditionally independent of the estimate of $\beta_{2}$ as long as it is random, i.e., $E\left(\varepsilon_{2, t} \mid f d_{t}^{k}\right)=0$.

Under mild assumptions, equation (17) may also be interpreted as a direct test of uncovered interest parity. If we rule out the presence of riskless arbitrage opportunities, then by covered interest parity the forward discount exactly equals the excess return paid on domestic securities relative to foreign securities:

$$
i_{t}^{k}-i_{t}^{*}=f d_{t}^{k}
$$

where $i_{i}^{k}$ and $i^{*}{ }_{t}^{k}$ are the domestic and foreign interest rates on instruments which mature in $k$ periods. Uncovered interest parity is thus the hypothesis that the interest differential is equivalent to investors' expectations of future depreciation. 20

\subsection{Results}

Table 6 reports the OLS regressions of equation (17). In some respects the data provide evidence in favor of perfect substitutability. All of the estimates of $\beta_{2}$ are statistically indistinguishable from one (with the sole exception of the

80 For tests of uncovered interest parity similar to the tests of conditional bias in the forward discount that we considered in section 3 , see Cumby and Obstfeld (1981). 
TABLE 6

TESTS OF PERFECT SUBSTITUTABILITY

OLS Regressions of E[as $(t+1)]$ on $f d(t)$

\begin{tabular}{|c|c|c|c|c|c|c|c|c|c|}
\hline Dat: Set & Dates & 8 & $t: B=.5$ & $t: B=1$ & $R$ & DF & DH & $\begin{array}{l}F \text { test } \\
a=0, B=1\end{array}$ & Prab $>F$ \\
\hline Econosist Data & $6 / 81-12 / 85$ & $\begin{array}{c}0.9880 \\
(0.1465)\end{array}$ & $3.33 \mathrm{ktt}$ & -0.08 & 0.89 & 554 & 1.44 & $28.6 !$ & 0.000 \\
\hline Econ 3 Month & $6 / 81-12 / 85$ & $\begin{array}{l}1.3037 \\
10.25571\end{array}$ & $3.14 \mathrm{ttt}$ & 1.19 & 0.70 & 184 & 1.56 & 16.55 & 0.000 \\
\hline Econ 6 Month & $6 / 81-12 / 85$ & $\begin{array}{l}1.0326 \\
(0.1694)\end{array}$ & $3.14 \mathrm{ttt}$ & 0.19 & 0.89 & 184 & 1.37 & 52.06 & 0.000 \\
\hline Econ 12 ronth & $6 / 81-12 / 85$ & $\begin{array}{c}0.9286 \\
(0.1499)\end{array}$ & 2.86111 & -0.48 & 0.91 & 184 & 1.44 & 65.82 & 0.000 \\
\hline mins 1 Month & $10 / 84-2 / 86$ & $\begin{array}{c}0.8416 \\
(1.7275)\end{array}$ & 0.20 & -0.09 & 0.21 & 171 & 1.02 & 6.79 & 0.000 \\
\hline mas 3 Month & $1 / 8.5-10 / 84$ & $\begin{array}{l}-0.1816 \\
(0.4293)\end{array}$ & -1.59 & $-2.75 t t t$ & 0.73 & 182 & 1.50 & 14.60 & 0.000 \\
\hline AMEX Data & $1 / 76-7 / 85$ & $\begin{array}{c}0.9605 \\
(0.2495)\end{array}$ & $1.85 t$ & -0.16 & 0.64 & 91 & 0.74 & 5.38 & 0.000 \\
\hline AMEX 6 Month & $1 / 76-7 / 85$ & $\begin{array}{c}1.2165 \\
(0.2085)\end{array}$ & 3.44111 & 1.04 & 0.71 & 45 & 1.45 & 6.32 & 0.000 \\
\hline AMEX 12 Month & $1 / 7 b-7 / 85$ & $\begin{array}{c}0.6770 \\
(0.2755)\end{array}$ & 1.37 & -0.45 & 0.61 & 45 & 0.51 & 8.10 & 0.000 \\
\hline
\end{tabular}

Notes: Method of Monents standard errors are in parentheses. Represents significance at the 10\% level, "th and the represent significance at the $5 \%$ and 14 levels, respectively. 
MMS three-month sample). In the Economist and Amex data sets which aggregate across time horizons, the estimates are 0.99 and 0.96 , respectively. ${ }^{21}$ Expectations seem to move very strongly with the forward rate. With the exception of the MMS data, the coefficients are estimated with surprising precision. As we might expect, however, the large magnitudes of the risk premia discussed in section 2 cause us to reject perfect substitutability. Each of the F-tests reported in Table 6 rejects the parity relation at a level of significance that is less than 0.1 percent.

In terms of our decomposition of the forward discount bias coefficient, Table 6 shows the values of $\beta_{r p}$ in column 2 of Table 5a are not significantly different from zero. Thus the rejection of unbiasedness found in the previous section cannot be explained entirely by the risk premium at any reasonable level of confidence. Indeed, in spite of the fact that the survey risk premium has substantial magnitude (Table 2), we cannot reject the hypothesis that the risk premium explains no positive portion of the bias.

Table 6 also reports a t-test of the hypothesis that $\beta_{2}=K$. In six out of nine cases the data strongly reject the hypothesis that the variance of the true risk premium is greater than or equal to that of true expected depreciation; we have rather $\operatorname{var}\left(\Delta \overline{\mathbf{s}_{\mathbf{t + k}}^{\mathbf{e}}}\right)>\operatorname{var}\left(\overline{\mathbf{r} \mathbf{p}_{\mathbf{t}}}\right)$. In addition, equation (18) and the finding that $\beta_{2}=1$ together imply that:

$$
\operatorname{var}\left(\overline{\mathbf{r} \mathbf{p}_{\mathbf{t}}}\right)+\operatorname{cov}\left(\Delta \overline{\mathbf{s}_{\mathbf{t}+\mathbf{k}}} \overline{\mathbf{r} \mathbf{p}_{\mathbf{t}}}\right)=0
$$

Thus we cannot reject the hypothesis that the covariance of true expected depreciation and the true risk premium is negative (as Fama found), nor can we

21 For the Economist six-month and twelve-month and the Amex twelve-month data sets, the estimates of $\beta_{2}$ from equation (17) do not exactly correspond to $1-\beta_{p}$ in Tables $5 a$ and $5 \mathrm{~b}$. This is because Table 6 includes a few survey observations for which actual future spot rates have not yet been realized, whereas these observations were left out of the decomposition in Tables $5 a$ and $5 b$ for purposes of comparability. If we had used the smaller samples in Table 6 , the regression coefficients would have been .82 and 1.03 , for the Economist and Amex data sets, respectively. 
reject the extreme hypothesis that the variance of the true risk premium is zero.

Note that the $R^{2}$ 's in Table 6 are relatively high. Under the null hypothesis that true expected depreciation exactly equals the forward discount, one could interpret these results as evidence that the measurement-error component of the survey data is relatively small. For example, under this interpretation of the $R^{2}$ statistics, measurement error accounts for about 10 percent of the variability in expected depreciation from the Economist survey. 22 The presence of a time-varying risk premium uncorrelated with the forward discount, however, implies that the disturbance term, $\varepsilon_{2, t}$, will not be purely measurement error but will also include variation of the risk premium around its mean. In this case a second interpretation of the $R^{2}$ measure is possible: that it overstates the measurement error component of the surveys. Indeed, the low values of the Durbin-Watson statistics reported in Table 6 seem to suggest the presence in the OLS residuals of a risk premium which is serially correlated but uncorrelated with the forward discount.

In Table 7 we correct for the potential serial correlation problem by employing a Three-Stage-Least-Squares estimator that allows for contemporaneous correlation (SUR) as well as first order auto-regressive disturbances. ${ }^{23}$ 3SLS is consistent here because there are no overlapping observations -- predictions by the forward rate and the surveys are observed contemporaneously -- and it has the advantage of being asymptotically efficient. The results reported in Table 7 show that this correction does not change the nature of the results; all but one of the coefficients remain close to one, and

22 Recall, however, that the $R^{2}$ measures in Table 6 include the explanatory power of the constant terms for each currency and forecast horizon.

es Unfortunately, the highly irregular spacing of the Amex data sets did not permit an auto-regressive correction in this case. 
TABLE 7

TESTS EF PERFECT SUBSTITUTABILITY

3SLS Regressions of E[ $\Delta s(t+1)]$ on $f d(t)$

\begin{tabular}{|c|c|c|c|c|c|c|c|}
\hline Data Set & Bates & $\mathrm{B}$ & $t: \theta=.5$ & $t: t=1$ & $\begin{array}{l}\text { verage } \\
p(1)\end{array}$ & $\mathrm{DF}$ & $\begin{array}{l}\text { Prob ; } F \\
a=0, \quad B=1\end{array}$ \\
\hline Econouist 3 Month & $6 / 81-12 / 85$ & $\begin{array}{c}0.8723 \\
(0.1327 !\end{array}$ & 2.81111 & -0.96 & 0.13 & 184 & 0.000 \\
\hline Econonist \& Month & $6 / 81-12 / 85$ & $\begin{array}{c}0.8768 \\
(0.0780)\end{array}$ & $4.83 \mathrm{ttt}$ & -1.58 & 0.32 & 184 & 0.000 \\
\hline Econonist 12 Month & $6 / 81-12 / 85$ & $\begin{array}{c}0.8378 \\
(0.0793)\end{array}$ & 4.26111 & $-2.04 \mathrm{tt}$ & 0.27 & 184 & 0.000 \\
\hline MS I Month & $10 / 94-2 / 86$ & $\begin{array}{l}-1.1535 \\
(1.0445)\end{array}$ & -1.58 & -2.06 & 0.21 & 171 & NA \\
\hline MHS 3 Month & $1 / 83-10 / 84$ & $\begin{array}{c}0.4672 \\
(0.3354)\end{array}$ & -0.10 & -1.59 & 0.33 & 179 & 0.000 \\
\hline
\end{tabular}

(1) Ayerage $p$ is the aean across courtries of the firct order auto-regressive coeficicients. Notes: Asyaptotic standard errors are in parentheses. Represents significance at the 10\% level, tt and ttt represent significance at the $5 \%$ and $1 \%$ levels, respectively. 
there is clear evidence that the variance of expected depreciation is greater than that of the risk premium (while there is no evidence for the alternative that the variance of the risk premium is greater).

\section{Tests of Rational Expectations}

In this section we test to see whether the interpretation of the standard bias findings in section 3 as evidence of systematic prediction errors can be supported. While in section 2 we found evidence that investors err in their unconditional forecasts of future changes in the spot rate, here we focus instead on whether investors tend to place too little weight on the contemparaneous spot rate and too much on all other information. Tests of rational expectations which address this question typically regress future prediction errors of the forward discount on subsets of the contemporaneous information set. As we have already noted, these tests are only valid in the absence of a risk premium. Consequently, we use here the prediction errors of the survey data instead.

\subsection{A Test of Excessive Speculation}

Perhaps the most powerful test of rational expectations is one which asks whether investors would do better if they placed more or less weight on the contemporaneous spot rate as opposed to all other variables in their information set.24 This test is performed by a regression of the expectational prediction error on expected depreciation:

$$
s_{t+k}^{e}-s_{t+k}=a+d \Delta s_{t+k}^{e}+v_{t+k}^{k}
$$

where the null hypothesis is $a=0$ and $d=0.25$ This is the equation that Bilson

24 Frankel and Froot (1986) test whether the survey expectations place too little weight on the contemporaneous spot rate and too much weight on specific pieces of information such as the lagged spot rate, the long-run equilibrium exchange rate, and the lagged expected spot rate.

R5 To see how the alternative in equation (20) is too much or too little weight on all variables in the information set other than the contemporaneous spot rate, assume expecta- 
(1981b) and others had in mind, which we already termed a test of "excessive" speculation, with the difference that we are measuring expected depreciation by the survey data instead of by the ambiguous forward discount.

Our tests are reported in Table 8. The findings consistently indicate that $d>0$, so that investors could on average do better by giving more weight to the contemporaneous spot rate and less weight to other information they deem pertinent. In other words, the excessive speculation hypothesis is upheld. Ftests of the hypothesis that there are no systematic expectational errors, $\boldsymbol{a}=\alpha=0$, reject at the one percent level for all of the survey data sets.

The results in Table 8 would appear to constitute a resounding rejection of rationality in the survey expectations. Up until this point, our test statistics have been robust to the presence of random measurement error in the survey data. But now, under the null hypothesis, measurement error biases toward one our estimate of $d$ in equation (20). The test of $d=0$, therefore, may reject more easily than the usual probability values would imply. To demonstrate this effect, suppose that expected depreciation as recorded by the survey is equal to the market's true expectation, $\Delta \overline{\mathbf{s}}_{\mathbf{t}+\mathbf{k}}$ plus an error term:

$$
\Delta \mathbf{s}_{i+k}^{*}=\Delta \bar{s}_{i+\mathbf{k}}+\xi_{i}
$$

where $\xi_{t+k}$ is iid and $E\left(\xi_{t} \mid \Delta \vec{s}_{t+k}^{\bullet}\right)=0$. The actual spot rate change can then be expressed as the sum of the true market expectation plus a prediction error:

tions are formed as a linear combination of the current spot rate, $s_{t}$, and any linear combination of variables in the information set, $\mathbf{I}_{t}$ :

If the actual process is:

$$
s_{t+k}^{*}=\pi_{1} I_{t}+\left(1-\pi_{1}\right) s_{t}
$$

Then equation (20) can be rewritten as

$$
s_{t+k}=\pi_{2} I_{t}+\left(1-\pi_{2}\right) s_{t}-\nu_{t+k}^{k}
$$

$$
\Delta s_{t+k}^{b}-s_{t+k}=a+\left(\pi_{1}-\pi_{2}\right)\left(I_{t}-s_{t}\right)+\nu_{t+k}^{t}
$$

Rational expectations is the case in which the coefficient $\pi_{1}-\pi_{2}$ is zero. A positive value implies $\pi_{1}>\pi_{2}$ : investors put insufficient weight on $s_{t}$ and too much weight on other in-
formation. 
TABLE 9

TESTS OF EXCESSIVE SPECULATION

Regressions of $E[s(t+1)]-s(t+1)$ on $E[\Delta s(t+1)]$

\begin{tabular}{|c|c|c|c|c|c|c|c|c|c|c|}
\hline Data Set & Dates & B & $t: B=0$ & & $t: B=1$ & R & $D F$ & DH & $\begin{array}{l}F \text { test } \\
a=0, B=0\end{array}$ & Prob $>F$ \\
\hline Econonist Data & $6 / 81-12 / 85$ & $\begin{array}{c}1.0162 \\
10.4104)\end{array}$ & 2.48 & & 0.04 & $0.4 ?$ & 509 & & 4.79 & 0.000 \\
\hline Econ 3 Month & $6 / 81-12 / 85$ & $\begin{array}{c}1.6141 \\
(0.4664\}\end{array}$ & $3.46:$ & tit & 1.32 & 0.26 & 184 & & 2.91 & 0.010 \\
\hline Econ 6 Month & $6 / 81-12 / 85$ & $\begin{array}{c}2.5325 \\
(0.6746)\end{array}$ & 3.75 & wit & 2.2711 & 0.41 & 174 & & 3.54 & 0.002 \\
\hline Econ 12 Month & $6 / 81-12 / 85$ & $\begin{array}{c}-0.3005 \\
(0.5241)\end{array}$ & -0.57 & & $-2.48 t t$ & 0.67 & 149 & & 6.32 & 0.000 \\
\hline MHS I Heek, I Honth & $10 / 34-2 / 36$ & $\begin{array}{l}(.2561 \\
(0.3544)\end{array}$ & 3.54 & 141 & 0.72 & 0.24 & 414 & & 6.07 & 0.000 \\
\hline Mis I Neek. & $10 / 84-2 / 86$ & $\begin{array}{c}1.1476 \\
(0.2939)\end{array}$ & 3.90 & t1! & 0.50 & 0.14 & 242 & 1.84 & 3.97 & 0.002 \\
\hline MiS I Heek, SUR & $10 / 84-2 / 86$ & $\begin{array}{c}0.7858 \\
10.11091\end{array}$ & 7.09 & tII & -1.93 & 0.18 & 239 & & 12.42 & 0.000 \\
\hline Mis I Month & $10 / 84-2 / 86$ & $\begin{array}{c}1.3068 \\
10.47411\end{array}$ & 2.76 & $t$ & 0.65 & 0.28 & 171 & & 3.11 & 0.010 \\
\hline MHS 2 Heek, 3 Month & $1 / 83-10 / 84$ & $\begin{array}{c}1.0494 \\
(0.3159)\end{array}$ & 3.32 & tit & 0.16 & 0.59 & 365 & & 7.87 & 0.000 \\
\hline MKS 2 Heek & $1 / 93-10 / 84$ & $\begin{array}{c}1.0594 \\
(0.2870)\end{array}$ & 3.69 & ant & 0.21 & 0.23 & 182 & 1.74 & 5.40 & 0.000 \\
\hline MHS 2 Week, SUR & $1 / 83-10 / 84$ & $\begin{array}{c}1.0469 \\
(0.1813)\end{array}$ & 5.77 & $\$ 4$ & 0.26 & 0.16 & 179 & & 9.42 & 0.000 \\
\hline MHS 3 Month & $1 / 83-10 / 84$ & $\begin{array}{l}1.0465 \\
(0.3895)\end{array}$ & 2.69 & 111 & 0.12 & 0.63 & 182 & & 7.59 & 0.000 \\
\hline AMEX Data & $1 / 76-7 / 85$ & $\begin{array}{c}2.6082 \\
10.5123\}\end{array}$ & 5.09 & 414 & $3.14 \mathrm{ttt}$ & 0.23 & 86 & & 4.71 & 0.000 \\
\hline AMEX 6 Month & $1 / 76-7 / 85$ & $\begin{array}{c}2.5693 \\
(0.7358)\end{array}$ & 3.49 & ttt! & 2.1344 & 0.37 & 45 & & 4.22 & 0.002 \\
\hline AMEX 12 Konth & $1 / 76-7 / 85$ & $\begin{array}{c}2.6382 \\
(0.5812)\end{array}$ & 4.54 & $\$ 4$ & 2.82144 & 0.50 & 40 & & 4.24 & 0.002 \\
\hline
\end{tabular}

Notes: All regressions except those marked SUR are estieated using OLS, with Method of Monents standard errors lin parentheses). SUR regressiouns report asyaptotic standard errors. Durbin-Hatson statistics are reported for data sets in which the forecast horizori is equal to the sampling interval. I Represents significance at

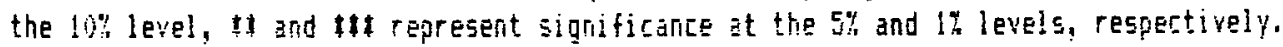




$$
\Delta \mathbf{s}_{t+k}=\Delta \mathbf{s}_{t+\mathbf{k}}^{*}+\eta_{t+k}^{k}
$$

Using these facts, the coefficient $d$ in equation (20) converges in probability to:

$$
d=\frac{\operatorname{var}\left(\xi_{t}\right)-\operatorname{cov}\left(\eta_{t+k}^{k}, \Delta \overline{\mathbf{s}_{\mathbf{t + k}}^{e}}\right)}{\operatorname{var}\left(\xi_{t}\right)+\operatorname{var}\left(\Delta \overline{\mathbf{s}_{\mathbf{t}+\mathbf{k}}^{\mathbf{e}}}\right)}
$$

Measurement error therefore biases our OLS estimates toward one. Indeed, in the limiting case in which the measurement error accounts for all of the variability of expected depreciation in the survey -- in other words, no information at all about the "true" market expectation is contained in the surveys -- the parameter estimate would be statistically indistinguishable from one. In Table 8, 13 of 15 estimates of $d$ are greater than one; in five cases the difference is statistically significant. This result suggests that measurement error is not the source of our rejection of rational expectations. However, we shall now see that stronger evidence can be obtained.

\subsection{Another Test of Excessive Speculation}

One way to get around this added source of noise is to use the projection of the survey expectations onto investors' information set as the right-hand-side variable in equation (20). Thus we seek a proxy for the survey expectations. The candidate must be highly correlated with the survey expected depreciation, and conditionally independent of the measurement error, $E\left(\xi_{t} \mid f d_{t}^{k}\right)=0$. In view of the results from section 4, the forward discount seems eminently qualified. The usual instrumental variables estimation procedure is not necessary in this case because the null hypothesis is that $d=0$. Thus we run the OLS regression:

$$
s_{t+k}^{*}-s_{t+k}=\alpha_{1}+\beta_{1} f d+\varepsilon_{1, t+k}^{k}
$$

and perform a test of rationality, $\alpha_{1}=\beta_{1}=0$. 
TABLE ?

TESTS OF RATIONAL EXPECTATIONS

OLS Regressions of $E[s(t+1)]-5(t+1)$ on $f d(t)$

\begin{tabular}{|c|c|c|c|c|c|c|c|}
\hline Data Set & Dates & B & $t: B=0$ & $R$ & $\mathrm{DF}$ & $\begin{array}{l}F \text { test } \\
a=0, \quad B=0\end{array}$ & Prob $>F$ \\
\hline Econonist Data & $6 / 81-12 / 85$ & $\begin{array}{c}1.4903 \\
(1.0580)\end{array}$ & 1.41 & 0.48 & 509 & 4.75 & 0.000 \\
\hline Econ 3 Month & $6 / 81-12 / 85$ & $\begin{array}{c}2.5127 \\
(1.2918)\end{array}$ & 1.95 & 0.14 & 184 & 1.31 & 0.256 \\
\hline Econ 6 Month & 6/81-12/85 & $\begin{array}{c}2.9866 \\
(1.5974)\end{array}$ & 1.87 & 0.28 & 174 & 1.46 & 0.194 \\
\hline Econ 12 Month & $6 / 81-12 / 85$ & $\begin{array}{c}0.5174 \\
(1.2290)\end{array}$ & 0.42 & 0.67 & 149 & 6.01 & 0.000 \\
\hline Mis I Month & $10 / 84-2 / 86$ & $\begin{array}{l}15.3945 \\
(6.3520)\end{array}$ & 2.4211 & 0.20 & 171 & 2.54 & 0.030 \\
\hline Whs 3 Honth & $1 / 8 j-10 / 84$ & $\begin{array}{c}6.0725 \\
(2.3392)\end{array}$ & $2.60 \$ 1$ & 0.66 & 182 & 11.93 & 0.000 \\
\hline AnEX Data & $1 / 76-7 / 85$ & $\begin{array}{c}3.2452 \\
(1.1675)\end{array}$ & $2.78 \div 14$ & 0.33 & 86 & 2.69 & 0.005 \\
\hline AnEX 6 Honth & $1 / 76-7 / 85$ & $\begin{array}{c}3.6346 \\
(1.3437)\end{array}$ & $2.70 t 4 t$ & 0.26 & 45 & 3.30 & 0.009 \\
\hline AMEX 12 Honth & $1 / 76-7 / 85$ & $\begin{array}{c}3.1081 \\
(1.2954)\end{array}$ & $2.40 \mathrm{it}$ & 0.25 & 40 & 1.48 & 0.210 \\
\hline
\end{tabular}

Notes: Method of homents standard errors are in parentheses. Represents significance at the $10 \%$ level, 11 and $\$ 4$ represent significance at the $5 \%$ and $1 \%$ levels, respectively. 
Equation (24) has additional relevance in the context of our decomposition of the forward rate unbiasedness regression in section 3 : the coefficient, $\beta_{1}$, is precisely equal to the deviation from unbiasedness due to systematic prediction errors, $\beta_{r e}$. Thus equation (24) can tell us whether the large positive values of $\beta_{\text {re }}$ found in column (1), Tables $5 a$ and $5 b$ are statistically significant.

Table 9 reports OLS regressions of equation (24). We now see that the point estimates of $\beta_{50}$ in Tables $5 \mathrm{a}$ and $5 \mathrm{~b}$ are measured with precision. The data continue to reject statistically the hypothesis of rational expectations, $\alpha_{1}=0, \beta_{1}=0$. They reject $\beta_{1}=0$, in favor of the alternative of excessive speculation. (Because the measurement error has been purged, the levels of significance are necessarily lower than those of Table 8.) Thus the result that $\boldsymbol{\beta}_{r z}$ is significantly greater than zero seems robust across different forecast horizons and different survey samples. In terms of the decomposition of the typical forward rate unbiasedness test in Table $5 \mathrm{a}$, we can now reject the hypothesis that all of the bias is attributable to the survey risk premium. Put differently, even after allowing for measurement error, it is still not possible to reject the hypothesis that all the bias consists of repeated expectational errors made by survey respondents, and that no positive portion of the bias can attributed to the survey risk premium. 


\section{CONCLUSIONS}

(1) The survey data indicate that forward rate prediction errors do not give insight into the nature of the risk premia as commonly thought. In all three surveys, the errors exhibit unconditional bias of a sign opposite to estimates of the risk premium from the survey data. The premia are large in absolute value, and are statistically different from zero. We can reject the hypothesis that systematic unconditional mistakes made by the forward rate in predicting the future spot rate are due entirely to a failure of rational expectations. But at the other extreme, the hypothesis that the forward rate prediction errors can be explained by the risk premium alone is also rejected.

(2) Expected depreciation is more variable than both the forward discount and the risk premium. The first finding corroborates Fama's (1984) conjecture that expected depreciation and the risk premium are negatively correlated. The second finding rejects the hypothesis that the variance of expected depreciation is less than the variance of the risk premium, let alone the more extreme random-walk hypothesis that the variance of expected depreciation is zero.

(3) Direct tests of perfect substitutability across assets denominated in different currencies produce mixed results. We find evidence against a timevarying risk premium, in the respect that changes in expected depreciation are on average matched, one for one, with changes in the forward discount. In terms of point (2), changes in the forward discount appear to be unrelated to changes in risk. The hypothesis of no risk premium fails in our regressions, however, because the level of expected depreciation is significantly different from the forward discount by a constant term. In short, while the survey data do support the existence of a substantial risk premium, they suggest that the many previous citations of forward discount bias as evidence for the exchange 
risk premium may have been misplaced.

(4) While changes in the forward discount reflect changes in expected depreciation, they seem to be, if anything, negatively related to future spot rate changes. Significantly negative coefficients in regression tests of forward discount unbiasedness, a common finding in many previous tests, are also found here. The survey data indicate that this large and significant deviation from unbiasedness is overwhelmingly due to repeated forecasting mistakes made by survey respondents. As in the unconditional case in point (1), we are unable to reject the hypothesis that the conditional deviation from unbiasedness is due entirely to a failure of rational expectations. We are able to reject the competing hypothesis that the deviation from unbiasedness is purely a consequence of the risk premium. The implication is that, when forming their expectations, investors would do better to put more weight on the contemporaneous spot rate, and less weight on all other variables on which they rely. This is the same result that Bilson and many others have found with forward market data; but now it cannot be attributed to a risk premium. 


\section{APPENDIX}

In this appendix we show how the asymptotic efficiency of the method-ofmoments estimator is affected by aggregating over forecast horizons. Consider the model:

$$
y_{t+k}^{k}=x_{t}^{k} \beta+\varepsilon_{t+k}^{k}
$$

where $y_{t+k}^{k}=Y_{t+k}-Y_{t}$ and the error term is orthogonal to the present and past values of $x$ and $y, E\left(\varepsilon_{t+k}^{k} \mid x_{t}^{k}, x_{t-1}^{k}, \cdots, y_{t}^{k}, y_{t-1}^{k}, \cdots\right)=0$. Our example below considers the simple case of a single regressor, $x_{t}^{k}$, but may easily be extended to a vector of righthand-side variables. Define the iid innovations $v_{t+k}=$ $E\left(y_{t}^{k} \mid x_{t}^{k}, x_{t-1}^{k}, \cdots, y_{t}^{k}, y_{t-1}^{k}, \cdots\right)$ and $\eta_{t+k}=E\left(x_{t}^{k} \mid x_{t}^{k}, x_{t-1}^{k}, \cdots, y_{t}^{k}, y_{t-1}^{k}, \cdots\right)$. If $x$ and $y$ are jointly covariance stationary, then the Wold decomposition implies that:

$$
\begin{gathered}
y_{t+k}^{k}=\sum_{i=0}^{\infty} \delta_{i} v_{t+k-i}+\sum_{i=0}^{\infty} \gamma_{i} \eta_{t+k-i}+D_{y}^{k} \\
E\left(y_{t+k}^{k} \mid \varphi_{t}\right)=\sum_{i=k}^{\infty} \delta_{i} v_{t+k-i}+\sum_{i=k}^{\infty} \gamma_{i} \eta_{t+k-i}+D_{y}^{k}
\end{gathered}
$$

where $D_{y}^{k}$ is the deterministic component of $y$, and $\varphi_{t}$ includes past and present values of $x$ and $y$. We are primarily concerned with the case in which $x_{t}^{k}$ is the best unbiased forecast of $y_{t+k}^{k}$. That is, under the null hypothesis of forward discount unbiasedness, $f d_{t}^{k}$ is an efficient predictor of the future spot rate change, $\Delta s_{t+k}$. Thus we assume that $x_{t}^{k}$ already contains all relevant information for forecasting $y_{t+k}^{k}$, so that $E\left(y_{t+k}^{k} \mid \varphi_{t}\right)=E\left(y_{t+k}^{k} \mid x_{t}^{k}\right)$.

We define analogously the $h$ period change in $Y_{t+h}$ as $y_{t+h}^{h}=\sum_{j=0} \sum_{i=0} y_{t+h-j k-i}^{k}$, where $h \equiv n k$. Using equations (A1) and (A2) we then have: 


$$
\begin{aligned}
y_{t+h}^{h}= & \sum_{j=0 i=0}^{n-1} \sum_{i} \delta_{i+h-j k-i}+\sum_{j=0 i=0}^{n-1} \sum_{i=1} \gamma_{i+h-j k-i}+D_{y}^{h} \\
E\left(y_{t+h}^{h} \mid \varphi_{t}\right) & =\sum_{j=0 i=h-j k}^{n-1} \infty \delta_{i} v_{t+h-j k-i}+\sum_{j=0 i=h-j k}^{n-1} \sum_{i} \gamma_{i} \eta_{t+h-j k-i}+D_{y}^{h}
\end{aligned}
$$

These facts imply that the $k$ and $h$ period prediction errors, $\varepsilon_{t+k}^{k}$ and $\varepsilon_{t+h}^{h}$, respectively, are stationary with finite second moments. If we assume that $q_{t}^{k}=\varepsilon_{t+k}^{k} x_{t}^{k}$ and $q_{t}^{h}=\varepsilon_{t+h}^{h} x_{t}^{h}$ are stationary with finite variance, then $E\left(q_{t}^{k} q_{t+j}^{k}\right)=0$ for $j \geq k$, and $E\left(q_{t}^{h} q_{t+j}^{h}\right)=0$ for $j \geq h$. Thus $q_{t}^{k}$ can be expressed as a $k-1$ order moving average process:

$$
q_{t}^{k}=\sum_{i=0}^{k-1} a_{i} \nu_{t+k-i}
$$

Similarly, from equation (A2') we have that $q_{t}^{h}$ may be written as a $h-1$ order moving average process:

$$
\begin{aligned}
q_{t}^{h} & =\sum_{j=0}^{n-1} \sum_{i=0}^{h-1} d_{i} \nu_{t+h-j k-i} \\
& =\sum_{j=0}^{n-1} \sum_{i=0}^{k}\left(c_{h-j k-i}+a_{k-i}\right) \nu_{t+h-j k-i}
\end{aligned}
$$

$$
n-2
$$

where $c_{h-j k-i}=\sum_{m=j} d_{(n-m) k-i}$. The covariance generating function for $q_{t}^{k}$ is denoted by $\lambda^{a}(z)$, where

$$
\lambda^{a}(z)=\sum_{s=1-k}^{k-1} \lambda_{s}^{a}=\sigma_{\nu}^{2} \sum_{s=1-k}^{k-1} \sum_{j=0}^{k-1} a_{j} a_{j+s}
$$

Using equation (A4), the covariance generating function for $q_{t}^{h}$ can be written as: 


$$
\lambda^{\alpha}(z)=\lambda^{c}(z)+\frac{n(n+1)}{2} \lambda^{\alpha}(z)+\frac{n(n-1)}{2} \lambda_{0}^{a}+2 \lambda^{a c 1}(z)
$$

where $\lambda^{a 1}(z)$ is a complicated generating function of the $a_{i}$ 's and $c_{i}$ 's which we need not specify here. Finally, the covariance generating function, $\lambda^{a d}(z)=$ $h-1 \quad h-1$

$\sigma_{\nu}^{2} \sum \sum a_{j} d_{j+s}$ can be rewritten as:

$:=1-k j=0$

$$
\lambda^{a d}(z)=\frac{(n+1)}{2} \lambda^{a}(z)+\frac{(n-1)}{2} \lambda_{0}^{a}+\lambda^{a c 2}(z)
$$

where $\lambda^{a c z}(z)$ is another generating function of the $a_{i}$ 's and $c_{i}$ 's.

Now consider the asymptotic MoM covariance matrix of $\sqrt{T}(\hat{\beta}-\beta)$ from equation (A1):

$$
\theta^{1}=\left(\lambda_{0}^{k}\right)^{-2} \lambda^{a}(z)
$$

$T$

where $\lambda_{0}^{k}={ }_{t \rightarrow-}^{1 m} T^{-1} \sum x_{t}^{k} x_{t}^{k}$. If we add in the longer-term forecast data, our model $t=1$

is that of equation (11) above, with asymptotic covariance matrix:

$$
Q^{2}=\left(\lambda_{0}^{h}+\lambda_{0}^{k}\right)^{-2}\left(\lambda^{d}(z)+\lambda^{a}(z)+2 \lambda^{a d}(z)\right)
$$

By substitution, we have that $\Theta^{1}>\Theta^{2}$ if and only if:

$$
>n^{2} / 2\left(1+\frac{\lambda_{0}^{\alpha}}{\lambda^{\alpha}(z)}\right)+n / 2\left(3+\frac{\lambda_{0}^{h}}{\lambda_{0}^{k}}\left(1+\frac{\lambda_{0}^{k}}{\lambda_{0}^{k}}\right)+\frac{\lambda^{a}(z)+\lambda^{c}(z)+2\left(\lambda^{a c 1}(z)+\lambda^{a c z}(z)\right)-\lambda_{0}^{a}}{\lambda^{a}(z)}\right.
$$

Equation (A9) says that the variance of the longer-term data, $\lambda_{0}^{h}$, must increase at a rate the same as or greater than the relative forecasting interval, $n$, if we are to gain by adding longer-term forecasts to data sets of only shorter-term forecasts. Thus as the forecasting interval increases, we require correspond- 
ingly greater variability of the regressors in order to compensate for the greater variability of the forecast errors.

One might think that the result in equation (A9) is a consequence of weighting the more imprecise longer-term predictions equally with the predictions of shorter-term. Perhaps if we downweighted the longer-term data, we would always gain in efficiency. It turns out that this is not the case. In the remaining space, we construct a consistent, optimally weighted estimator and show that the efficiency of this estimator may still worsen asymptotically by adding in the longer-term forecasts.

In most circumstances. GLS represents the optimal weighting strategy when the data have different levels of precision. GLS is, however, inconsistent when used on a model with overlapping observations. Thus we consider instead a weighted least squares estimator which is optimal within a class of consistent estimators. Consider a transformation of the model in equation (11), which stacks the shorter- and longer-term data:

$$
W \mathbf{y}_{t}=W \mathbf{x}_{t} \beta+W \nu_{t}
$$

where $W$ is a diagonal matrix. The MoM estimate of $\beta$ in equation (A10), $\hat{\beta}_{y}$, will be consistent for any arbitrary diagonal matrix $W$. To see this, note that the MoM estimate of equation (A10), $\hat{\boldsymbol{\beta}}_{\mathbb{Y}}$, may be written as:

$$
\begin{aligned}
\sqrt{T}\left(\hat{\beta}_{W}-\beta\right) & =\left(\frac{\mathrm{x}_{2 N \mathrm{NT}} W^{2} \mathrm{x}_{\mathrm{aNT}}}{T}\right)^{-1} \frac{\mathrm{x}_{2 N \mathrm{~T}} W^{2} \nu}{\sqrt{T}} \\
& =\left(\frac{1}{T} \sum_{i=1}^{2 T} x_{i}^{2} w_{i i}^{2}\right)^{-1} \frac{1}{\sqrt{T}} \sum_{i=1}^{R T} x_{i} \nu_{i} w_{i i}^{2}
\end{aligned}
$$

The final term in equation (A11) converges in probability to zero, provided that the error term in equation (A10) is conditionally independent of the contem- 
poraneous value of the regressor, $E\left(\nu_{t} \mid \mathbf{x}_{t}\right)=0$ (this is just the Gauss-Markov assumption required for the consistency of OLS in estimating equation (A10)). Suppose now that we choose $W$ optimally in order to maximize the gain in efflciency from adding longer-term forecasts to our shorter-term data. That is:

$$
\max ^{1}-\Theta^{3}
$$

where $\mathcal{O}^{\mathbf{s}}$ is the MoM asymptotic covariance matrix of $\hat{\beta}_{\mathbf{v}}$ :

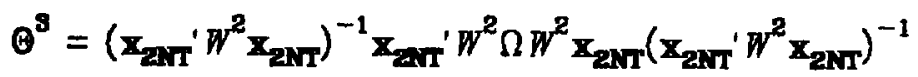

By normalizing the weight on every shorter-term data point to one, it is straightforward to show that the optimal weight placed on each longer-term observation is:

$$
w_{h} \cdot\left(\frac{\lambda_{0}^{k} \lambda^{a}(z)-\lambda_{0}^{k} \lambda^{a d}(z)}{\lambda_{0}^{k} \lambda^{d}(z)-\lambda_{0}^{h} \lambda^{a d}(z)}\right)^{k /}
$$

Note that $w_{h}^{*}$ will always be positive if the data sets are uncorrelated, i.e. if $\lambda^{a d}(z)=0$. In other words, appropriately weighted independent information can always improve efficiency, no matter how imprecise the new information may be. But, the nature of the correlation between contemporaneous longerterm and shorter-term predictions implies that the optimal weight given to longer-term data may be zero. In particular, $w_{h}^{*}$ will be zero if the numerator in equation (A14) becomes negative. This occurs if $n$ is too large in comparison with the relative variance of the longer-term forecasts. Using equations (A5'). (A6) and (A14), it can be shown that a sufficient condition for $w_{h}^{*}$ to be zero is:

$$
\frac{(n+1)}{2}>\frac{\lambda_{0}^{h}}{\lambda_{0}^{k}} .
$$

Thus, while the standard errors reported in the text indicate that for small values of $n$ one may obtain improvements in efficiency, this result is not likely 
to apply MoM estimation of data with considerably longer forecast horizons, even when the data are downweighted to account for the greater variance of the longer-term forecast errors. It is worth stressing in closing that this potential loss in efficiency is a direct consequence of our limited information MoM estimation strategy. Full information techniques, such as maximum likelihood estimation, will consistently achieve nonzero gains in asymptotic efficiency with the addition of longer-term data. 


\section{REFERENCES}

Bilson, John, "The Speculative Efficiency Hypothesis," Journal of Business, July $1981,54,435-51$ (1981a).

"Profitability and Stability in International Currency Markets," NBER Working Paper, No. 664, April 1981 (1981b).

"Macroeconomic Stability and Flexible Exchange Rates", American Economic Review, May 1985, 75, 62-67.

Boothe, Paul and David Longworth, "Foreign Exchange Market Efficient Tests: Implications of Recent Empirical Findings," Journal of International Money and Finance, 1986.

Cumby, Robert, and Maurice Obstfeld, "Exchange Rate Expectations and Nominal Interest Differentials: A Test of the Fisher Hypothesis," Journal of Finance, 1981, 36, 697-703.

Dornbusch, Rudiger, "Exchange Rate Risk and the Macroeconomics of Exchange Rate Determination," in R. Hawkins, R. Levich, and C. Wihlborg, eds., The Internationalization of Financial Markets and National Economic Palicy. Greenwich, Conn., JAI Press, 1983.

Fama, Eugene, "Forward and Spot Exchange Rates," Journal of Monetary Economics, $1984,14,319-338$.

Frankel, Jeffrey A., "The Diversifiability of Exchange Rate Risk," Journal of International Economics, 1979, 9, 379-393.

"In Search of the Exchange Risk Premium: A Six-Currency Test Assuming Mean-Variance Optimization," Journal of International Money and Finance, 1982, 1, 255-274.

"The Implications of Mean-Variance Optimization for Four Questions in International Macroeconomics," Journal of International Money and Finance, 1985.

Frankel, Jeffrey A. and Kenneth A. Froot, "Using Survey Data to Test Some Standard Propositions Regarding Exchange Rate Expectations," NBER Working Paper, No. 1672. Revised as IBER Working Paper, No. 86-11, University of California, Berkeley, May 1986.

"The Dollar as a Speculative Bubble: A Tale of Fundamentalists and Chartists," NBER Working Paper, No. 1854. March 1986.

Gregory, Allan W., and Thomas H. McCurdy, "Testing the Unbiasedness Hypothesis in the Forward Foreign Exchange Market: A Specification Analysis," Journal of International Money and Finance, 1984, 3, 357-368. 
Hansen, Lars Peter, "Large Sample Properties of Generalized Method of Moments Estimators," Econometrica, 1982, 50, 1029-1054.

Hansen, Lars and Robert Hodrick, "Forward Rates as Optimal Predictors of Future Spot Rates: An Econometric Analysis," Journal of Political Economy. October 1980, 88, 829-53.

Hodrick, Robert, and Sanjay Srivastava, "An Investigation of Risk and Return in Forward Foreign Exchange," Journal of International Money and Finance. April 1984, 3, 5-30.

Expected Future "The Covariation of Risk Premiums and 1986.

Huang, Roger, "Some Alternative Tests of Forward Exchange Rates as Predictors of Future Spot Rates," Journal of International Money and Finance August $1984,3,157-67$.

Krasker, William, "The 'Peso Problem' in Testing the Efficiency of Forward Exchange Markets," Journal of Monetary Economics, April 1980, 6, 269-76.

Levich, Richard, "On the Efficiency of Markets of Foreign Exchange," in R. Dornbusch and J. Frenkel, eds., International Economic Policy. Johns Hopkins University Press, Baltimore: 1979, 246-266.

Litterman, R.B. "Bayesian Procedure for Forecasting with Vector Autoregressions," M.I.T., 1980.

Longworth, David, "Testing the Efficiency of the Canadian-U.S. Exchange Market Under the Assumption of No Risk Premium," Journal of Finance. March $1981,36,43-49$.

McCulloch, J.H., "Operational Aspects of the Siegal Paradox," Quarterly Journal of Economics, February 1975, 89, 170-172.

Mussa, Michael, "Empirical Regularities in the Behavior of Exchange Rates and Theories of the Foreign Exchange Market," Carnegie-Rochester Series on Public Policy, Autumn 1979, 11, 9-57.

Newey, Whitney and Kenneth West, "A Simple, Positive Definite, Heteroskedasticity and Autocorrelation Consistent Covariance Matrix," Woodrow Wilson School Discussion Paper, No. 92, May 1985.

Tryon, Ralph, "Testing for Rational Expectations in Foreign Exchange Markets," Federal Reserve Board International Finance Discussion Paper, No. 139, 1979. 